\title{
Políticas de apoyo a las familias en Europa: nuevos contextos y nuevas orientaciones $^{1}$
}

\author{
Joseba Zalakain \\ SIIS Centro de Documentación y Estudios, Fundación Eguía-Careaga \\ $<$ jzalakain@siis.net>
}

Artikulu honetan, lehenik aztertzen dira EAEko familia-politikak (ber)diseinatzean kontuan hartu beharreko testuinguru sozioekonomikoan oraintsu gertaturiko ondorengo aldaketa batzuek: jaiotzatasaren beherapena, desberdintasunaren hazkundea, seme-alabak dituzten familietako pobreziaren hazkundea eta desberdintasunaren erreprodukzioan familia-herentziaren gero eta garrantzi handiagoak duen eragina gorako mugikortasun sozialeko aukeren murriztean. Horren ondoren deskribatzen ditu Europako familia-politiken arloan garatzen ari diren paradigma, eredu edo orientazioak -hein batean, aipaturiko aldaketa sozioekonomiko horiei erantzunez-, eta horiek aplikatu daitezke, edo aplikatu beharko lirateke, Euskadiko ondorengo familia-politikaren arloetan: inbertsio soziala, arreta goiztiarraren garrantzia, aurrez eginiko banaketaren ikuspegia, familia-prestazioen fiskalizazioa eta gurasotasun positiboa. Azterketa horretatik abiatzen dira gomendio edo orientazio batzuek Euskadiko familia-sostengurako politiketarako.

\section{GAKO-HITZAK:}

Familia-politika, inbertsio soziala, familientzako laguntzak, arreta goiztiarra, aldaketa soziala, Euskadi, Europar Batasuna.
Este artículo analiza, en primer lugar, algunos cambios recientes en el contexto socioeconómico que deben considerarse a la hora de (re)diseñar las políticas familiares en la CAPV: el descenso de la natalidad, el incremento de la desigualdad, el crecimiento de la pobreza entre las familias con hijos/as y la reducción de las posibilidades de movilidad social ascendente como consecuencia del creciente peso de la herencia familiar en la reproducción de la desigualdad. Seguidamente, describe los paradigmas, modelos u orientaciones que se están desarrollando en el ámbito de las políticas familiares en Europa -en parte como respuesta a los cambios socioeconómicos señalados- y que podrían, o deberían, aplicarse en las políticas familiares en Euskadi: la inversión social, la importancia de la atención temprana, el enfoque de la predistribución, la fiscalización de las prestaciones familiares y la parentalidad positiva. A partir de ese análisis, se plantean algunas recomendaciones u orientaciones para redefinir las políticas de apoyo a las familias en Euskadi.

\section{Palabras Clave:}

Política familiar, inversión social, ayudas a la familia, atención temprana, cambio social, País Vasco, Unión Europea.

${ }^{1}$ Este artículo recoge los contenidos de la ponencia presentada por el SIIS Centro de Documentación y Estudios en los XXXIII Cursos de Verano de la UPV/EHU y las XXIX Jornadas de Coordinación de Defensores del Pueblo, organizadas por el Ararteko, bajo el título genérico de 'Las familias y sus necesidades y retos en el actual entorno social y económico: respuesta de los poderes públicos'. 


\section{Introducción}

El objetivo de este artículo es analizar de qué manera se han adaptado las políticas de apoyo a las familias de los países de la UE al nuevo contexto social y económico marcado, entre otros aspectos, por la crisis económica iniciada en 2008 . Con ello, se pretende extraer algunas lecciones o aprendizajes que contribuyan a reorientar las políticas de apoyo a las familias que se realizan en la Comunidad Autónoma del País Vasco (CAPV) -y, de forma genérica, en el Estado español- a los cambios en el contexto económico, social, político y demográfico que cabe prever para los próximos años.

La estructura del artículo es la siguiente:

- En primer lugar, se analizan algunos de los cambios que se han producido en el contexto social, político y demográfico, y que tienen un efecto determinante en la configuración de las políticas familiares. Si bien no son los únicos, los que se consideran más importantes son el incremento del desempleo y la desigualdad, con una afectación especialmente intensa entre los grupos sociales más desfavorecidos; el incremento de la pobreza infantil, o entre las familias con hijos/as, y el desplazamiento del riesgo de pobreza a la población infantil y juvenil; el estrangulamiento de las posibilidades de movilidad social ascendente y el peso creciente de la transmisión familiar de capital-económico y cultural- en la reproducción de la desigualdad; y la (re)emergencia del problema de la natalidad. No se abordan en este trabajo, aunque sin duda son cuestiones relevantes, la emergencia de nuevos modelos familiares y el cambio en los patrones que rigen las relaciones intrafamiliares.

- En segundo lugar, se analizan los principales paradigmas, enfoques u orientaciones que están determinando en Europa las políticas de atención a las familias y a la infancia, con particular atención al paradigma de la inversión social, el énfasis en la primera infancia, la idea de la predistribución o el bienestar basado en el patrimonio (asset based welfare), el recurso creciente a las herramientas fiscales, y el desarrollo de políticas y programas de parentalidad positiva.

- Finalmente, se recogen las principales conclusiones del análisis realizado y se plantean algunas recomendaciones de cara a la necesaria reorientación de las políticas de apoyo a las familias en la CAPV.

\section{Un nuevo contexto para las políticas de apoyo a las familias}

\subsection{Globalización, precarización laboral, paro y desigualdad}

Junto con la emergencia de nuevos modelos familiares y el cambio en los patrones de relación intrafamiliar (cuestiones que, por motivos de espacio, no se abordan en este artículo ${ }^{2}$ ), no cabe duda de que el nuevo panorama socioeconómico que se deriva de la actual crisis económica afecta claramente a las familias y a la orientación de las políticas familiares a medio y largo plazo. El efecto -suficientemente conocido- de la crisis económica en términos de crecimiento del desempleo, la precarización laboral, la exclusión y la desigualdad ${ }^{3}$ debe contextualizarse, en cualquier caso, en un marco social, político y económico más amplio, que va a condicionar en los próximos años el papel de las familias, sus funciones y su capacidad de garantizar el bienestar de todos sus miembros. De forma muy resumida, los cambios contextuales más importantes vienen determinados por:

- La emergencia de una economía globalizada, con una competencia internacional mucho mayor que en el pasado, y en la que, en países como el nuestro, la cualificación profesional juega un papel cada vez más relevante. Como se señala en detalle en las páginas siguientes, en el marco de la economía del conocimiento, en países como Euskadi las personas sin suficientes cualificaciones profesionales tendrán posibilidades de inclusión laboral y de movilidad social más reducidas.

- La crisis del proceso de construcción europea y el papel crecientemente residual de los países de la UE en un mundo en el que -tanto desde el punto de vista económico como político o demográficoganan peso los países emergentes y los del área del Pacífico.

- El agotamiento, especialmente en el caso del Estado español, de un modelo productivo de bajo coste, basado en el crédito externo y el empleo precario y de bajos salarios, en la construcción y en sectores de escaso valor añadido.

- La extensión del empleo de bajos salarios y del fenómeno de los trabajadores pobres, asociada a la emergencia del precariado como grupo social, que implica un cambio en la propia naturaleza de la pobreza (ya no sólo vinculada al desempleo o a la vejez) y requiere una reorientación de las políticas de inclusión.

- La emergencia de los llamados nuevos riesgos sociales, como la dependencia o la monoparentalidad, y un cierto agotamiento de los modelos clásicos del Estado de bienestar, amenazados,

2 El reciente informe extraordinario del Ararteko sobre políticas familiares en la CAPV dedica a este asunto una amplia atención (Ararteko, 2014).

${ }^{3}$ Basta señalar al respecto que, de acuerdo con las Estadísticas Comunitarias sobre la Renta y las Condiciones de Vida (EU-SILC) [Eurostat], entre 2004 y 2012 la ratio S8o/20 ha pasado del 5,2 al 7,2 en España (lo que quiere decir que la distancia entre el $20 \%$ más rico y el $20 \%$ más pobre se ha incrementado casi en un $40 \%$ ), mientras que en la UE15 crecía del 4,8 al 5,1. En la CAPV, por el contrario, según la Encuesta de Pobreza y Desigualdades Sociales, habría pasado de 3,9 en 2004 a 3,7 en 2012 (Departamento de Empleo y Asuntos Sociales, 2012). En lo que se refiere a la exclusión social, de acuerdo con los datos de la Encuesta sobre Integración y Necesidades Sociales (Comité Técnico de la Fundación Foessa, 2014), los hogares en situación de integración plena han pasado de representar en 2007 el 50,1\% de la población al 34,3\% en 2012 . 
de una parte, por una ofensiva ideológica que justifica las políticas de austeridad y recortes en función del déficit público provocado por la crisis, pero también por otros cambios (envejecimiento de la población, crecimiento de los costes unitarios asociados a los servicios sociales y de salud, mayores demandas de control y autonomía por parte de las personas beneficiarias de servicios sociales) que dificultan la viabilidad económica y social del Estado de bienestar clásico, y obligan a aplicar fórmulas innovadoras para preservarlo.

En este contexto, muchos de cuyos elementos son

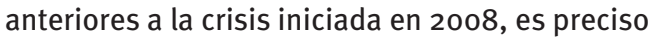
también insistir en la idea de que los efectos de la crisis no se han distribuido por igual entre toda la población, y que han sido los sectores tradicionalmente más desfavorecidos (lo que ya fueron "perdedores en tiempos de bonanza", en palabras de Sebastiá Sarasa [2008]), los que en mayor medida se han visto perjudicados por la crisis. Pese al discurso social imperante, cabe pensar que las clases medias y acomodadas han sido afectadas por la crisis en menor medida que las clases menos favorecidas, y que el efecto de la recesión se ha concentrado en unos colectivos muy determinados: jóvenes, inmigrantes, personas de baja cualificación, autónomos, trabajadores/as con contrato temporal y familias jóvenes con hijos/as a cargo.

Es cada vez más clara la evidencia del efecto diferencial de la crisis, lo que obliga a contextualizar el incremento de la desigualdad al que se ha hecho anteriormente referencia: "Somos desiguales porque nuestros pobres son mucho más pobres que los pobres de los países de nuestro entorno. Somos un país más desigual que nuestros vecinos no porque nuestra clase media sea particularmente pobre en relación a los más ricos, sino porque nuestra clase baja es particularmente pobre respecto a la clase media" (Fernández-Albertos, 2014). La propia OCDE ha puesto de manifiesto que, durante la crisis, los hogares pobres han sido quienes en mayor medida han visto reducir su renta, y es precisamente en España donde la diferencia entre la reducción de ingresos de las clases medias y la reducción de ingresos de las clases menos favorecidas ha sido más acusada (OCDE, 2014). Hay numerosos datos que permiten sostener esta afirmación, frente al discurso general del debilitamiento de las clases medias:

- En 2011, teniendo en cuenta a las personas menores de 65 años, la renta de las personas de la quinta decila (es decir, las situadas en el centro de la escala de ingresos) multiplicaba por 2,7 la renta del $10 \%$ más pobre (es decir, casi triplicaban su renta). Antes de la crisis, la diferencia era menor (2,2 veces). En 2011, de todos los países de la OCDE respecto a los que hay datos, sólo Grecia, Israel y Estados Unidos registraban una distancia más amplia entre las clases medias y las de menor renta. Sin embargo, si se analiza la brecha entre los muy ricos y la clase media ( $\left.\mathrm{S}_{90} / 50\right)$, la distancia era menor, ha variado poco durante la crisis (de 1,9 a 2,1) y, en España, es algo más cercana a la media de la OCDE.

- De acuerdo con la Encuesta de Condiciones de Vida (INE, 2014), la tasa de riesgo de pobreza y exclusión (tasa AROPE) entre la población autóctona ha pasado del $21 \%$ en 2007 al $25 \%$ en 2012. Entre la población extranjera, ha pasado del $32 \%$ al $53 \%$ : si antes de la crisis era casi un $50 \%$ más alta, ahora esa diferencia se ha doblado.

- Según la misma encuesta, el porcentaje de hogares con cuatro o más carencias materiales ha pasado, en el caso del $30 \%$ de la población más pobre, del $11 \%$ en 2008 al $17 \%$ en 2012. En el caso de las decilas medias -las personas que se sitúan en las decilas 4 a 7-, el porcentaje ha pasado del $4,1 \%$ a $4,3 \%$.

Las razones de ese mayor efecto diferencial de la crisis en las clases menos favorecidas se relacionan, fundamentalmente, con la menor protección frente al riesgo de desempleo de los colectivos que con más frecuencia tienen contratos laborales temporales (mujeres, jóvenes, inmigrantes), frente a la elevada protección de la que aún hoy gozan las personas con contrato indefinido. En ese marco, el ajuste se realiza prescindiendo del empleo temporal y la destrucción de empleo castiga especialmente a colectivos vulnerables. Junto con la dualización del mercado laboral - con una brecha entre insiders y outsiders que sigue siendo determinante para explicar la desigualdad social-, también cabe hacer referencia a un sistema de impuestos y prestaciones menos redistributivo que en la mayor parte de los países de la UE4. En el caso español, la escasa capacidad redistributiva del sistema de prestaciones e impuestos se deriva de la combinación de dos elementos: a) un sistema de protección social rudimentario, que no protege de los nuevos riesgos sociales, ajeno al discurso de la inversión social, poco progresivo y muy dependiente de apoyos corporativos; $y b$ ) una presión fiscal que se sitúa entre las más bajas de Europa, muy dependiente además de los ingresos tributarios que se derivaban de la burbuja inmobiliaria, con niveles muy elevados de fraude y poco progresivo.

En la CAPV, como se hemos visto, la desigualdad de ingresos es menor que en otros países de Europa, y no parece que los indicadores de desigualdad empeoraran sustancialmente entre 2008 y 2012. Además, los datos de la Encuesta de Pobreza y Desigualdades Sociales (Departamento de Empleo y Asuntos Sociales, 2012) evidencian que, si bien la pobreza se ha incrementado de forma notable en ese periodo (en torno a un $30 \%$ ), también lo ha hecho el porcentaje de personas en hogares en situación de completo bienestar, que no tienen carencias ni en lo que se refiere a sus ingresos, ni a su patrimonio ni condiciones de vida. El peso de este grupo es,

4 De acuerdo también a la OCDE (2014), España es uno de los países en los que el $30 \%$ de la población con menores ingresos recibe unas prestaciones más bajas (en relación a las transferencias medias), y en los que el $30 \%$ más rico recibe prestaciones más elevadas. 
en 2012, el más elevado de toda la serie histórica cubierta por la encuesta ( $37 \%$ ) y contrasta con el $20 \%$ registrado en $2000^{5}$.

\subsection{La emergencia de la pobreza infantil y el creciente riesgo de pobreza de las familias con hijos/as}

En ese contexto, en el que, como hemos visto, la pobreza y la desigualdad han afectado de forma muy diferente a los diversos grupos sociales, las familias con hijos/as a cargo están expuestas a un riesgo creciente de pobreza. Numerosos estudios han puesto de relieve -tanto para la CAPV como para el conjunto de los países de la UE- la emergencia en los últimos años del fenómeno de la pobreza infantil, que no es otra cosa que la pobreza entre las familias con hijos $/ a^{6}$, y, en términos más generales, el desplazamiento del riesgo de pobreza de la población mayor hacia la población infantil y juvenil. Como se ha señalado en otros trabajos, resulta evidente que en Europa se ha producido un 'redescubrimiento' del fenómeno de la pobreza infantil, debido, por una parte, al desplazamiento de los mayores riesgos de pobreza a la población infantil y juvenil, y, por otra, a la constatación del efecto que estas situaciones tienen a corto, medio y largo plazo en las condiciones de vida de la infancia, en sus expectativas vitales y en sus oportunidades de desarrollo e integración. Desde esta perspectiva, la pobreza infantil se considera no

${ }^{5}$ Estos datos parecen poner de relieve un cierto proceso de polarización social y permiten pensar que los efectos de la crisis -al menos en su primera fase- no están teniendo las mismas implicaciones en los distintos grupos de población: en efecto, la pobreza y la precariedad afectan cada vez más a los grupos tradicionalmente considerados de riesgo, afectados por las dificultades crecientes de acceso a una ocupación estable, mientras que, de hecho, las tasas de pobreza se reducen entre los colectivos más favorecidos de la sociedad, cuantitativamente mayoritarios. Esta mejora en la situación de determinados grupos y la polarización social que implica resultan del máximo interés, en la medida en que cuestionan la percepción social mayoritaria sobre las consecuencias de la crisis económica sobre las clases medias y permiten pensar en que un amplio sector de la población todavía cuenta con recursos económicos suficientes para sortear los efectos más negativos de la crisis.

${ }^{6}$ Obviamente, la pobreza infantil se refiere a los niños y niñas -al margen de la edad que se establezca para determinar el final de la infancia- que viven en situaciones de pobreza. En nuestro entorno, sin embargo, si se deja al margen la situación de los menores inmigrantes no acompañados, no existen niños o niñas pobres, sino familias pobres y, fundamentalmente, padres y madres que perciben ingresos insuficientes para mantener unos niveles de vida mínimos para ellos/as y para sus hijos e hijas. Por definición, los niños y niñas pobres lo son porque lo son sus familias y, más concretamente, porque lo son sus progenitores. Por lo tanto -al menos desde el punto de vista de su definición y de la identificación de sus causas-, la cuestión relevante no se refiere tanto a la pobreza infantil como a la pobreza de las familias con hijos/as y, por tanto, a la insuficiencia de los ingresos de sus padres y madres. Desde este punto de vista, parece claro que enfatizar excesivamente el concepto de pobreza infantil implica una visión reduccionista del problema. Todo ello no impide, sin embargo, reconocer la necesidad de desarrollar políticas específicamente centradas en la prevención y el abordaje de la pobreza infantil, tanto en lo que se refiere a reducir la incidencia de la pobreza entre las familias con hijos/as (abordando los factores de riesgo específicos que subyacen a estas situaciones) como a reducir el efecto que la pobreza tiene en las condiciones de vida y en las perspectivas de futuro de los niños y niñas que se encuentran en esa situación, mediante medidas compensatorias, y apoyos sociales y socioeducativos adecuados (SIIS Centro de Documentación y Estudios, 2013). sólo un atentado a los derechos de los niños y niñas afectados, sino una amenaza seria a la equidad, a la cohesión social e, incluso, a la productividad futura de las sociedades europeas (SIIS Centro de Documentación y Estudios, 2013).

La creciente prevalencia de la pobreza entre las familias con hijos/as se produce tanto a escala de la CAPV como del Estado español o del conjunto de la UE. El Gráfico 1 recoge la evolución del indicador de riesgo de pobreza en la UE y en el Estado español para las familias con hijos/as y para las familias sin hijos/as. Como se observa, la tasa de pobreza de las familias con hijos en España ha pasado del $22 \%$ al $27 \%$ entre 2007 y 2012, mientras que en la UE15 lo ha hecho del $17 \%$ al $18 \%$. En el caso de las familias sin hijos, el crecimiento de la pobreza ha sido menor en España (aunque ello pueda deberse a la reducción de la renta mediana que se utiliza como parámetro para el cálculo de las tasas de pobreza) y apenas ha variado en la UE. La diferencia entre ambos grupos no ha dejado de crecer tanto en la UE como en España, si bien en España lo ha hecho de forma mucho más acusada: si en 2004 la tasa de pobreza de las familias con hijos/as a cargo multiplicaba por 1,1 la de quienes no tenían hijos/as a cargo, en 2013 prácticamente la duplicaba (se multiplicaba por 1,7).

También en Euskadi la pobreza infantil es un fenómeno creciente. De acuerdo con la Encuesta de Pobreza y Desigualdades Sociales (EPDS) de 2012 (Departamento de Empleo y Asuntos Sociales, 2012), un total de 33.864 menores de 14 años viven en Euskadi en una situación de riesgo de pobreza de mantenimiento $0^{7}$, lo que representa el $11,8 \%$ de esa población. En torno a otros 30.000 (el 10,5\%) viven en una situación de ausencia de bienestar, con lo que el porcentaje de niños/as en riesgo de pobreza o en ausencia de bienestar alcanza el 22,3\% del total. El $77,7 \%$ restante vive en una situación de bienestar ${ }^{8}$.

La citada encuesta, que representa la estadística oficial sobre pobreza en la CAPV y se realiza desde hace casi treinta años, se diferencia de los enfoques convencionales de medición de la pobreza al establecer el umbral de pobreza en función de la percepción subjetiva de la población respecto a los ingresos mínimos necesarios para cubrir las necesidades básicas. En el caso de las situaciones de pobreza, la EPDS distingue entre pobreza de mantenimiento, pobreza de acumulación y pobreza real. La pobreza de mantenimiento hace referencia a aquellas formas de pobreza relacionadas con una insuficiencia de ingresos o de rentas para abordar las necesidades ordinarias, esto es, aquellas a las que debe hacerse frente a corto plazo. En términos concretos, en cuanto a su significado real en la vida cotidiana, la pobreza de mantenimiento hace referencia a una situación de insuficiencia de recursos económicos para abordar, a corto plazo, la cobertura de las necesidades básicas, particularmente las relacionadas con los gastos de alimentación, vivienda, vestido y calzado. Dentro de la dimensión de mantenimiento, la EPDS distingue entre las situaciones de pobreza y las de ausencia de bienestar, y fija en 2012 -para una familia de 4 miembros encabezada por una persona menor de 45 años- el umbral de pobreza en unos 1.500 euros, y el de ausencia de bienestar, en 1.970 euros.

${ }^{8}$ Pese a la gravedad de la actual crisis, la tasa de riesgo de pobreza de mantenimiento infantil está por debajo de la registrada en 1996 y en una línea sólo algo superior a la de 2000. Otro de los elementos sustancialmente distintos de la situación en 2012 es la continua reducción en el porcentaje de menores en situación de ausencia de bienestar, lo que lleva a una estabilización -en términos históricamente altos- de la población infantil en situación de bienestar desde el punto de vista de la dimensión de mantenimiento. En 


\section{España}

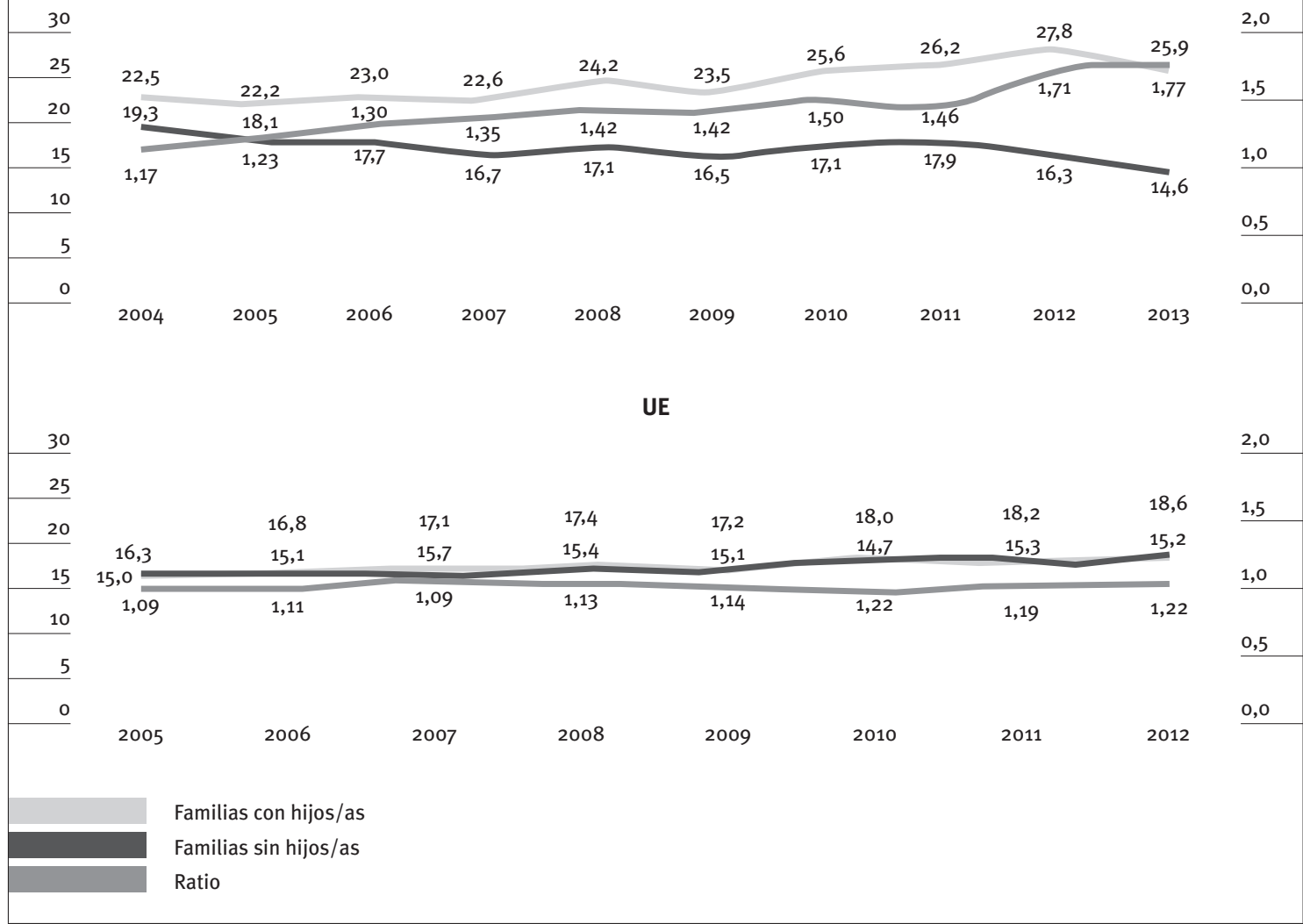

* Las personas en riesgo de pobreza son las que pertenecen a unidades familiares que perciben ingresos inferiores al $60 \%$ de la renta mediana equivalente de su país.

Fuente: Estadísticas Comunitarias sobre la Renta y las Condiciones de Vida (EU-SILC) [Eurostat].

La situación en 2012 se deriva, en cualquier caso, de una lógica que se inicia más atrás. El Gráfico 2 indica, por una parte, que la pobreza infantil es, desde al menos 1996, más elevada que la del conjunto de la población y que si ambas tasas fueron convergiendo poco a poco entre 1996 y 2004 , a partir de ese año la diferencia se fue incrementando. En 2012, la tasa de pobreza en los menores de 14 años equivalía al $161 \%$ de la tasa correspondiente al conjunto de la población.

En el mismo sentido, el Gráfico 3 recoge la evolución de la incidencia de la pobreza de mantenimiento por tramos de edad, describiendo la situación a lo largo de los últimos dieciséis años. El cambio que se ha ido produciendo en el patrón que rige las diferencias en las tasas de pobreza por grupos de edad es claro: a mediados de los noventa, las tasas de pobreza formaban una curva en forma de 'U', siendo los dos grupos situados a ambos extremos -los menores de 14 y los mayores de 65- quienes padecían tasas de

otras palabras, al menos desde 2004, están creciendo fuertemente las situaciones de pobreza infantil y, un poco más ligeramente, las de bienestar, reduciéndose por el contrario el peso de quienes están en una situación intermedia, de ausencia de bienestar, más cercana a la precariedad.
Gráfico 2. Evolución de la tasa de pobreza de mantenimiento del conjunto de la población y de la población menor de 14 años, y diferencia entre la tasa infantil y la global*. CAPV, 1996-2012 (\%)

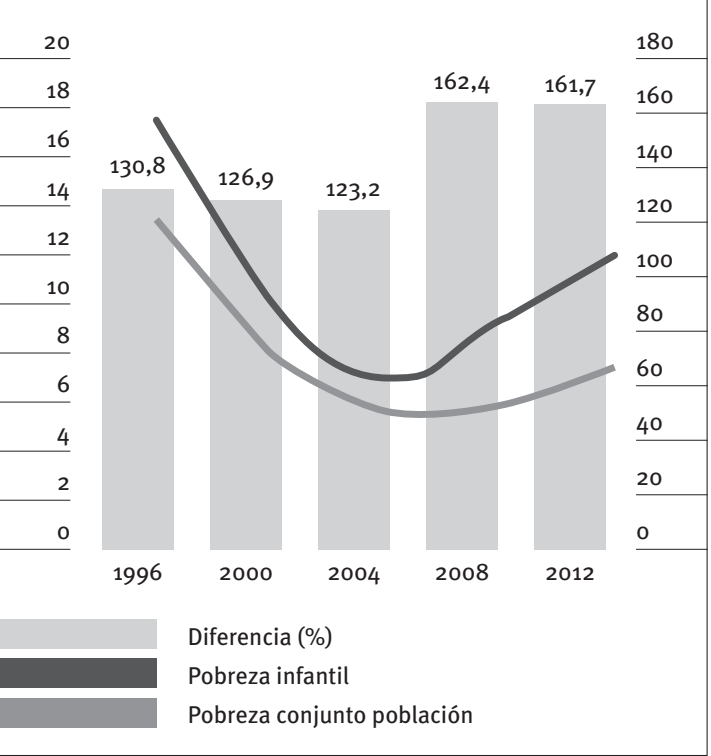

* Tasa global $=100$.

Fuente: Elaboración propia a partir de Departamento de Empleo y Asuntos Sociales (2012). 
pobreza más altas. En 2000, se mantiene la forma de esa curva, si bien la pobreza resulta bastante más elevada entre los mayores que entre los niños y la diferencia entre éstos y los tramos de edad intermedia resulta menor. En 2004, la 'U' se abre todavía más, en una época de reducción generalizada de las tasas de pobreza, con menores diferencias entre los grupos de edad, pero, en cualquier caso, manteniéndose en los dos extremos los valores más elevados.
El cambio más importante comienza a operarse en 2008: la curva en forma de 'U' desaparece para convertirse en una línea descendente, aunque irregular, en la que cuanto menor es la edad, menor es también, en líneas generales, el riesgo de pobreza. Ese cambio se acentúa en 2012, y la línea descendente se hace aún más clara, dejando al margen el repunte en las tasas de pobreza que se produce en la población de 25 a 34 años.

Gráfico 3. Evolución de la incidencia de la pobreza de mantenimiento*, por grupos de edad. CAPV, 1996-2012
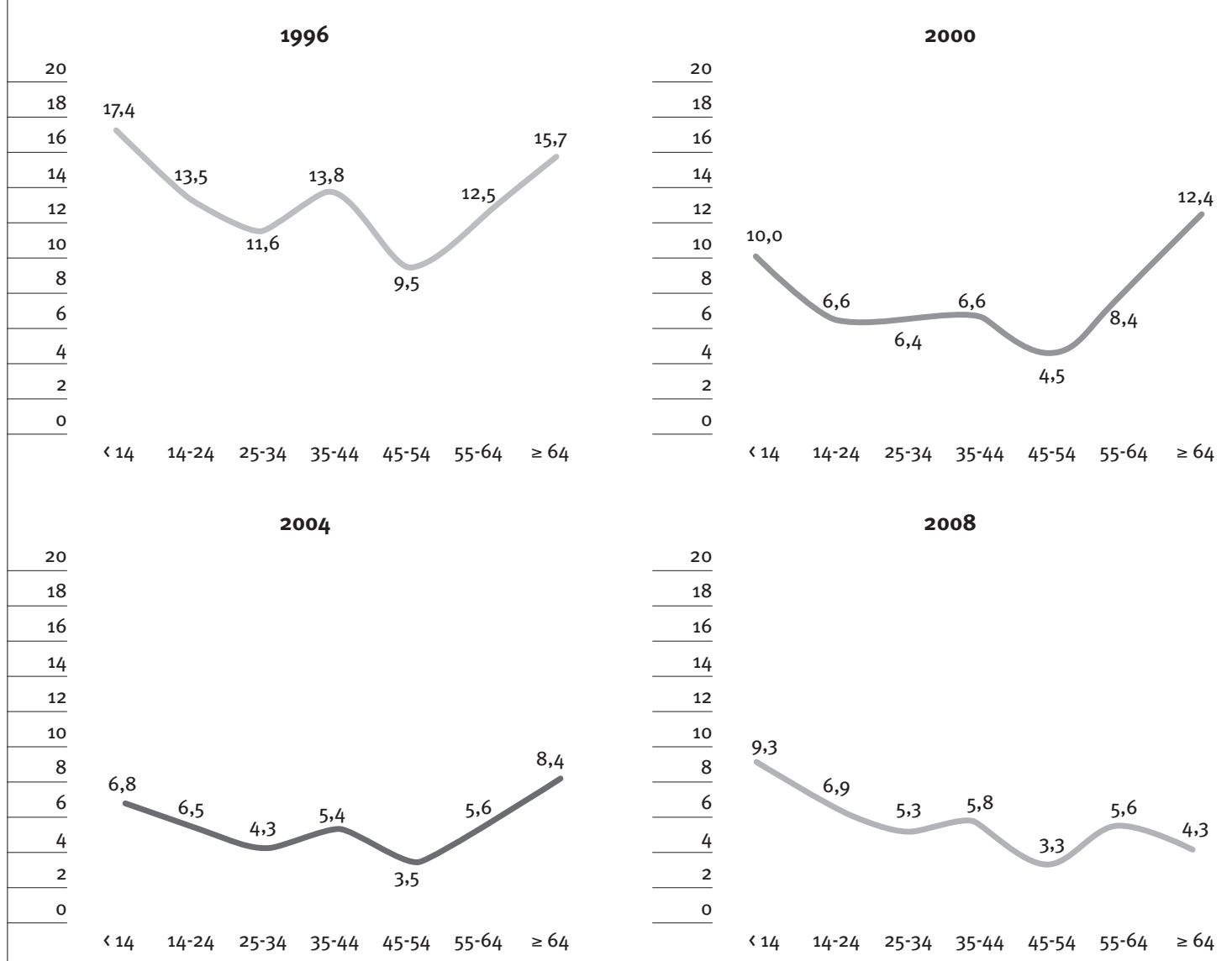

2012

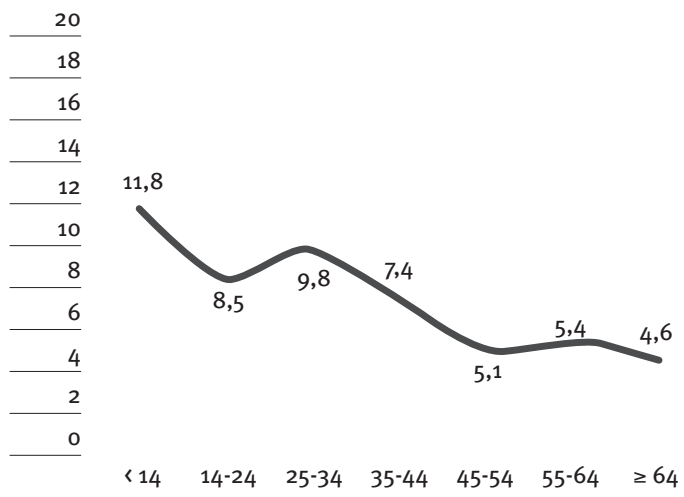

* Indicadores ajustados (base 2012).

Fuente: Departamento de Empleo y Asuntos Sociales (2012). 
Finalmente, cabe destacar el creciente peso de la infancia dentro del colectivo de personas en situación de pobreza. Si en 2000 los mayores de 65 años representaban el $27 \%$ de ese grupo, en 2012 apenas llegan al $12 \%$. Los menores de 14 años, por su parte, han pasado de suponer el $14 \%$ de todas las personas en riesgo de pobreza de la CAPV a representar el $21 \%$. El mayor cambio, en cualquier caso, se observa si se tiene en cuenta que, en 2000 , el $39 \%$ de las personas en situación de pobreza era menor de 35 años, mientras que en 2012 ese grupo etario supera el $50 \%$, pese a su pérdida de peso demográfico. El perfil de la pobreza en Euskadi es, por tanto, en 2012, mayoritariamente infantil y juvenil.

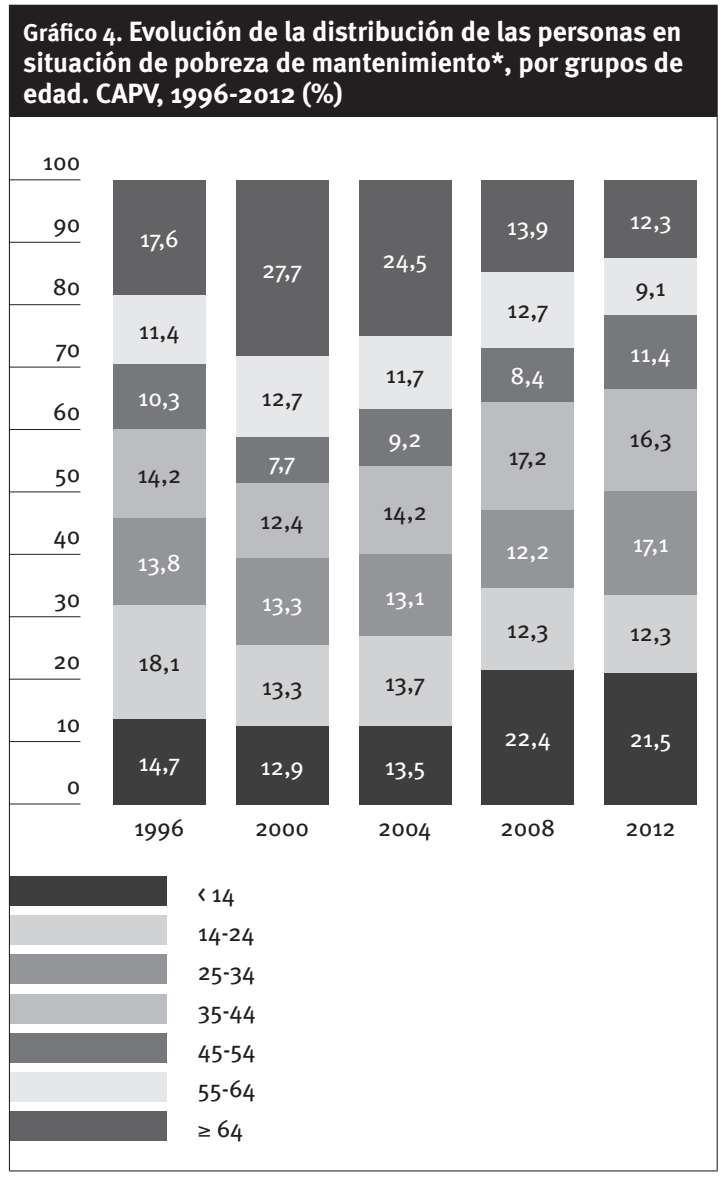

* Indicadores ajustados (base 2012).

Fuente: Departamento de Empleo y Asuntos Sociales (2012).

Los elementos que se acaban de citar -incremento de las tasas de pobreza infantil, situación cada vez más desfavorecida de la infancia frente a otros grupos de población, y creciente peso de la infancia y las familias con hijos/as dentro de la población en situación de pobreza- justifican, sin duda, la necesidad de adoptar políticas específicamente centradas en esta cuestión, tal y como han hecho la mayor parte de los países de nuestro entorno.
2.3. Una cuestión familiar: el peso creciente de la herencia en los procesos de movilidad social y en la reproducción de la desigualdad

\subsubsection{Desigualdad, crisis económica y movilidad social}

Uno de los efectos más importantes que -desde el punto de vista de las políticas familiares- puede tener el incremento de la pobreza y la desigualdad tiene que ver con las menores posibilidades de movilidad social ascendente y con la (re)emergencia de la cuestión de la herencia social, en un contexto marcado por la degradación de las oportunidades de ascenso social. Como señala Camille Peugny (2013), "el origen social vuelve a ser determinante en el itinerario vital de las personas. La dualización de la estructura social entre perdedores y ganadores de la globalización polariza de nuevo los destinos sociales y hace aún más estrechas las vías de movilidad social”. Existe, sin duda, una evidencia científica creciente que apunta a que las oportunidades vitales individuales siguen estando tan determinadas por el origen social como lo estaban en la época de nuestros padres o nuestros abuelos. A juicio de EspingAndersen (2005), además de sus consecuencias en términos de justicia social, la persistencia de la reproducción generacional de la desigualdad plantea hoy un problema mayor que en el pasado, si tenemos en cuenta el tipo de conocimientos y habilidades que, en el contexto de la economía del conocimiento, serán necesarios en un futuro próximo para mantener unas condiciones de vida razonables. Con las desigualdades en aumento, señala este autor, la capacidad de las familias para invertir en el futuro de sus hijos/as se irá volviendo también más desigual.

De acuerdo con la OCDE (2009), casi todas las dimensiones del bienestar en la edad adulta -estado de salud, ingresos, educación, inteligencia, conducta, personalidad u ocupación- se transmiten en cierta medida de los progenitores a sus hijos/as y es cada vez mayor la preocupación en los países occidentales por el efecto de la transmisión intergeneracional de la desigualdad. Para este organismo, si bien no hay datos que indiquen con claridad que la desigualdad intergeneracional esté aumentando en los últimos años, las investigaciones más recientes ponen de manifiesto que el nivel que alcanza este fenómeno es más alto de lo que se pensaba hasta hace algunos años, y que es en los extremos de la escala de rentas -las personas más pobres y las más ricas- donde el peso de la herencia familiar resulta más fuerte, es decir, donde la movilidad social es más baja y se tiende con mayor facilidad a reproducir el nivel educativo, social o de ingresos de la familia de origen. Los estratos medios de renta, por el contrario, estarían más expuestos a la movilidad social, tanto ascendente como descendente. Como señala EspingAndersen (2005), “el problema central de la herencia social radica en los extremos. Los hijos e hijas de las familias pobres se encuentran con barreras extraordinarias para avanzar en la escala social; por el contrario, los hijos e hijas de las familias ricas disfrutan 


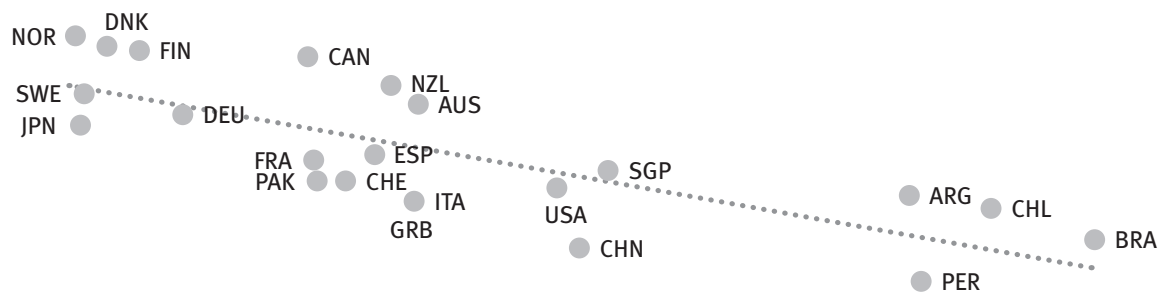

de una extraordinaria protección frente al riesgo de descenso social".

En cualquier caso, lo que sí está ampliamente demostrado es la relación entre la desigualdad imperante en una sociedad en un momento dado y su grado de movilidad social. Como se observa en el Gráfico 5 , los países nórdicos, con tasas de desigualdad muy reducidas, registran también tasas de elasticidad intergeneracional de ingresos (es decir, de reproducción social) muy bajas, mientras que los países con mayor desigualdad son los que tienen una menor movilidad (salvo Canadá, Australia y, en cierta medida, España ${ }^{9}$. La relación entre movilidad social y desigualdad no se produce sólo cuando la desigualdad se mide en el momento actual, sino también cuando se mide en el pasado, de forma que cuanto mayor ha sido la desigualdad en la generación anterior, menor resulta la movilidad intergeneracional en la generación siguiente. Este fenómeno es ampliamente reconocido y se conoce como 'curva del Gran Gatsby' (Corak, 2013).

En el caso español, los expertos alertan de que la actual situación de crisis económica e incremento de la desigualdad está poniendo fin al proceso generalizado de ascenso social que se venía experimentando desde hace décadas. Así, de acuerdo con los datos de Martínez Celorrio y Marín Saldo (2012) -que no se basan en datos de ingresos, sino en la autoadscripción de las personas a una clase social o estatus ocupacional determinado-, las posibilidades de ascenso social fueron incrementándose en España entre las décadas de 1970 y 1990, asimilándose a las pautas europeas de movilidad, para reducirse sin embargo en la primera década del siglo XXI. En este sentido, si la movilidad social española se analiza en función de las cohortes de edad, los datos apuntan a que las generaciones más jóvenes empiezan a tener

${ }^{9}$ En el caso español, la elasticidad intergeneracional de ingresos es, según la OCDE, de 0,40 , lo que implica que el $40 \%$ de la ventaja 0 desventaja de los progenitores se traslada a los hijos/as. Esa tasa de elasticidad es algo más baja de la que le correspondería a España en función de su elevado nivel de desigualdad. menos posibilidades de ascenso social que sus predecesoras ${ }^{10}$. De acuerdo con esos mismos autores, "el repunte de la herencia obrera y el elevado cierre social por arriba perfilan un escenario tendente a la rigidez, donde buena parte de la movilidad social sucede en la zona intermedia [...], que recibe fundamentalmente el ascenso obrero de corto recorrido y el escaso descenso procedente de la clase experta" (ibídem: 150) ${ }^{11}$.

Así pues, si bien la reactivación económica de mitad de los años ochenta, el proceso de modernización empresarial y del sistema productivo, la ampliación y consolidación de las políticas y estructuras de un Estado de bienestar de corte socialdemócrata y el ingreso en Europa, entre otras causas, hicieron posible un desarrollo inédito de las oportunidades de ascenso social intergeneracional -muy por encima de la media europea, sobre todo en el caso de los hombres, y debido fundamentalmente al importante aumento del nivel educativo de la población-, este proceso de ascenso social intergeneracional y las bases sobre las que se asentó se están viendo amenazados por la actual crisis económica (Martínez Celorrio y Marín Saldo, 2012).

${ }^{10}$ Para llegar a esta conclusión, los autores analizan las pautas de movilidad social de ocho cohortes generacionales, la primera de las cuales corresponde a personas nacidas entre 1942 y 1946, y la última, a personas nacidas entre 1977 y 1981. Las tasas de ascenso social más elevadas (en torno al $43 \%$ ) se producen en las cohortes nacidas entre 1957 y 1976. Las tasas de descenso más elevadas (en torno al $25 \%$ ) corresponden a las dos cohortes de mayor edad (nacidas entre 1942 y 1951) y a la más joven. Si bien es cierto que la situación de esta última puede estar determinada por su propia juventud, al no haber concluido todavía su proceso de enclasamiento, los autores consideran que también puede ser debido a la crisis económica. En ese sentido, señalan, se está produciendo "un cambio regresivo de tendencia, que hace empeorar el enclasamiento de los más jóvenes, aún más agravado e incierto con la actual política de austeridad y recortes en plena recesión" (ibídem: 148).

${ }^{11}$ Uno de los principales estudios longitudinales británicos, el British Cohort Study, pone también de manifiesto una notable reducción de la movilidad social ascendente entre las cohortes nacidas en 1958 y 1970 , si bien esta menor movilidad social se observa cuando se analiza la movilidad desde el punto de vista de los ingresos, pero no de la clase social (Blanden, Gregg y Macmillan, 2013). 


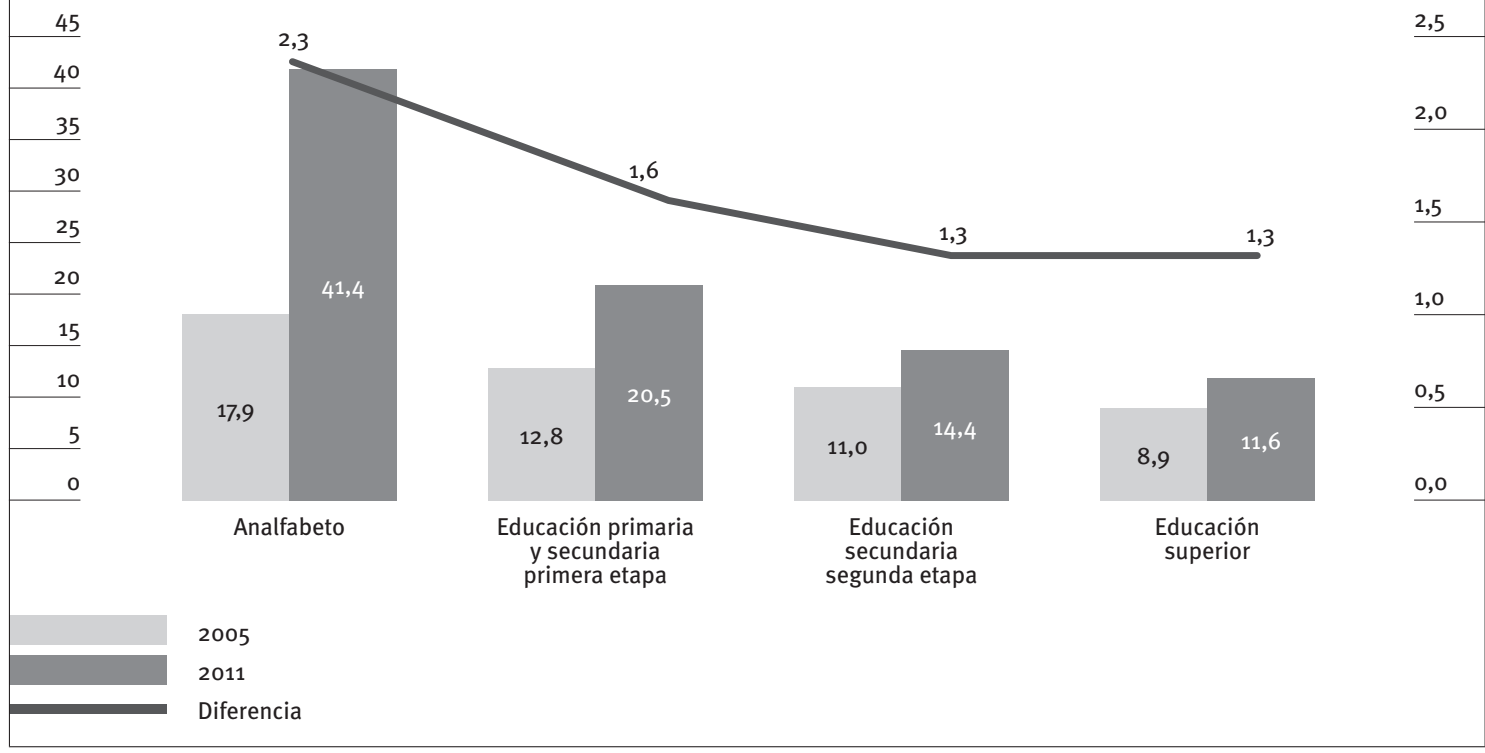

Fuente: Elaboración propia a partir de los módulos específicos sobre transmisión intergeneracional de la pobreza de Encuesta de Condiciones de Vida (INE, 2014).

Los datos apuntan efectivamente a que el peso del origen familiar tiene, en la actual situación socioeconómica, un efecto diferencial en el riesgo de pobreza: las personas que provienen de familias pobres 0 desfavorecidas no sólo tienen un mayor riesgo de pobreza, sino que la distancia que las separa en este aspecto de las personas que provienen de familias más acomodadas ha crecido en el periodo de crisis. Este efecto se ve con claridad si se analizan las tasas de pobreza, en 2005 y en 2011, de la población de 25 a 60 años en función del nivel de estudios que alcanzó su padre cuando esas personas eran adolescentes. Como se observa en el Gráfico 6, tanto en 2005 como en 2011, cuanto menor es el nivel educativo paterno, más elevadas son las tasas de pobreza. Lo más significativo, en cualquier caso, es que entre 2005 y 2011, durante el periodo de crisis, la tasa de pobreza de los hijos e hijas de personas sin formación se ha multiplicado por 2,3, mientras que entre los hijos e hijas de padres con secundaria de segunda etapa o superior se ha incrementado en una medida mucho menor $(1,3)$. De ello cabría deducir, en primera instancia al menos, que el origen familiar -medido en función del nivel formativo del padrees en la actual situación económica más determinante que antes de la crisis como factor de riesgo o protección en relación a la pobreza ${ }^{12}$.

Algunos estudios relacionan también la aparente reducción en las posibilidades de movilidad social ascendente con la emergencia de la pobreza infantil, a la que antes se ha hecho referencia. En ese sentido, el informe de la Comisión Independiente sobre Movi-

${ }^{12} \mathrm{El}$ efecto es similar, aunque algo menos claro, si se analiza el tipo de ocupación paterna durante la adolescencia. lidad Social promovida por el Gobierno británico en 2009 insiste en que cualquier estrategia de fomento de la movilidad social debe hacer hincapié en la pobreza infantil. Por supuesto, señalan los responsables de esta comisión, reducir la pobreza infantil no se limita a incrementar los ingresos económicos de las familias; también se necesita abordar los elementos subyacentes a la pobreza y las desventajas concretas que genera. Sin embargo, un nivel de ingresos razonable es esencial para una mínima calidad de vida y es un requisito básico para la movilidad social (Independent Comission on Social Mobility, 2009). De hecho, el Reino Unido ha establecido recientemente una comisión independiente que asesora al Gobierno -y evalúa sus políticas- en materia de pobreza infantil y promoción de la movilidad social, consideradas como las dos caras de una misma moneda.

En resumen, una creciente evidencia científica sugiere que la mayor desigualdad de ingresos que se registra en la actualidad hace que el contexto familiar juegue un papel cada vez importante a la hora de determinar el nivel de vida futuro de los jóvenes, mientras que se debilita la influencia que el esfuerzo personal tiene en las condiciones de vida futuras (Corak, 2013). Para este autor, la explicación de la curva del Gran Gatsby radica en la heredabilidad de determinadas características entre padres e hijos o, por decirlo de otra forma, en una desigual dotación inicial de capital. Este capital estaría formado tanto por los recursos económicos transmitidos de padres a hijos/as como por elementos como la reputación y las conexiones de la familia de origen, la carga genética o los aprendizajes, habilidades y objetivos adquiridos mediante la participación en una determinada cultura familiar. 


\subsubsection{El peso creciente de la riqueza heredada en el acceso al bienestar}

La forma más obvia de herencia, si bien no la única, es la correspondiente a la transmisión intergeneracional de los recursos económicos, a lo largo del ciclo vital -mediante donaciones- 0 a la muerte de los progenitores -mediante la figura de la herencia-. En ese sentido, uno de los economistas que ha alcanzado en los últimos años una mayor resonancia pública, Thomas Piketty, ha puesto de manifiesto cómo la transmisión intrafamiliar de la riqueza (especialmente de las grandes fortunas) es uno de los factores que en mayor medida explican en la actualidad el incremento de la desigualdad. A su juicio, el peso de la herencia familiar en la reproducción de las desigualdades viene creciendo desde hace décadas, y lo seguirá haciendo en el futuro si se mantienen las actuales condiciones socioeconómicas (Piketty, 2008). Para Piketty, si bien la magnitud y la concentración de la riqueza heredada fueron reduciéndose desde finales del siglo XIX hasta mediados del XX, no han dejado de incrementarse desde entonces ${ }^{13} \mathrm{y}$ no parece que, salvo cambios importantes en las actuales condiciones socioeconómicas, dicha tendencia vaya a revertir a corto o medio plazo (Piketty y Zucman, 2014).

A juicio de este autor, "la forma más obvia de corregir la injusta persistencia de la desigualdad que implica la transmisión familiar de la riqueza sería la tributación de las herencias y la redistribución de los ingresos fiscales a toda la población" (Piketty, 2008). Si bien algunos modelos económicos plantean que este tipo de tributación puede ser contraproducente a largo plazo de cara a la reducción de la desigualdad, Piketty sostiene que los modelos más realistas sugieren la necesidad de que "exista de forma permanente una tributación redistributiva de las herencias de cara a reducir permanentemente la transmisión intergeneracional de la desigualdad por la vía de la herencia” (ibídem).

Desde el ámbito de la filosofía política, también se ha evidenciado la importancia de la herencia en la reproducción intergeneracional de la desigualdad, y se ha abogado por un replanteamiento de las figuras fiscales relativas a las sucesiones y las donaciones. En ese sentido, Prabhakar, Rowlingson y White (2008) señalan que las herencias se distribuyen de forma desigual y que ello contribuye a la desigualdad en el reparto de la riqueza, lo que indica la existencia de un conflicto entre la institución de la herencia, en su forma convencional, y el principio de igualdad de oportunidades. Desde tal perspectiva, estos autores han defendido la necesidad de mantener y reforzar el impuesto de sucesiones a partir de tres argumentos: el de la igualdad de oportunidades, el de la justicia
${ }^{13}$ De acuerdo con Piketty, en Francia, por ejemplo, el peso de los bienes heredados en relación a la renta nacional pasó, entre 1880 y 1950 , del $25 \%$ al $5 \%$, para incrementarse hasta el $15 \%$ en 2010 . La evolución ha sido similar, aunque menos acusada, en el Reino Unido y Alemania (Piketty y Zucman, 2014).

${ }_{14}$ De acuerdo con el primer argumento, en la medida en que la
Más allá del debate sobre la relación entre el impuesto de sucesiones y la movilidad social ${ }^{15}$, la propia OCDE ha puesto de manifiesto que existe un nexo claro entre la movilidad social intergeneracional y la existencia de sistemas fiscales y de protección social de carácter redistributivo. Uno de documentos monográficos más reciente editados por esa entidad en torno a este asunto (OCDE, 2010) evidencia, precisamente, una relación muy clara entre la progresividad del sistema fiscal y la movilidad social, medida a través del efecto del nivel educativo paterno en el salario de la población ocupada.

\subsubsection{Movilidad social e inversión en capital humano: el papel de la educación}

Es importante subrayar, en cualquier caso, que la herencia familiar no se limita a la riqueza económica, y que también se trasmiten de padres a hijos determinadas habilidades, capacidades, expectativas, valores y relaciones que determinan las posibilidades de movilidad social de las personas. De hecho, como antes se ha señalado, el capital relacional, cultural y educativo de los progenitores está llamado a tener un peso cada vez mayor en una sociedad en la que el trabajo manual poco cualificado será cada vez más escaso y peor pagado. En la sociedad del conocimiento, las oportunidades vitales de las personas dependen de forma cada vez más acusada del capital cultural, social y cognitivo acumulado desde los primeros años de la infancia: de todo ello se deriva que las principales formas de desigualdad y las principales fuentes de exclusión provienen en la actualidad -y lo harán en mayor medida en el futuro- de la diferente capacidad de las familias para ofrecer, en los primeros años de vida, los estímulos y aprendizajes necesarios en ese nuevo contexto (SIIS Centro de Documentación y Estudios, 2012a).

Sin duda, la principal inversión en capital humano que las familias realizan es la inversión en educación, y no es de extrañar que la educación se considere un elemento esencial en las dinámicas de movilidad

desigualdad de la herencia se materializa en desigualdad de oportunidades, el impuesto de sucesiones permite neutralizar esa desigualdad y favorece una mayor igualdad de oportunidades. Desde el punto de vista de la justicia fiscal, White et al. argumentan la injusticia que supone que las rentas de trabajo sean sometidas a tributación, en algunos casos elevada, y no lo sean en cambio ingresos, en ocasiones muy elevados, recibidos mediante herencia. Finalmente, desde el punto de vista de la cultura democrática, los autores mantienen que la renuncia a la tributación de las herencias, y del patrimonio en general, tiene un efecto corrosivo en la cohesión social y en la cultura democrática de un país, en la medida en que implica un tratamiento más favorable a unos grupos determinados y en que cuestiona el principio del mérito sobre el que, en teoría, se asienta el Estado social y de derecho.

${ }^{15} \mathrm{~A}$ diferencia de lo que ocurre con otros impuestos, como el de sociedades o el de patrimonio, la cuestión del impuesto de sucesiones está en gran medida ausente del debate fiscal en Euskadi. Tal ausencia es difícil de entender si se tiene en cuenta la escasa presión fiscal a la que está sometida la transmisión del patrimonio en Euskadi, comparada con la de muchos países de la UE. En 2011, se recaudaron en la CAPV cerca de 77 millones de euros mediante el impuesto de sucesiones y donaciones, que equivalían al o,1\% del PIB. Según la OCDE, ese mismo año Francia recaudó con este impuesto un 0,4\% de su PIB; Bélgica, un 0,7\%; Dinamarca, un 0,3\%; los Países Bajos, un $0,3 \%$; y España, un 0,2\%. 
social. Para la OCDE, el capital humano es un determinante fundamental del nivel de ingresos individual y de su productividad, y la educación es un determinante clave del capital humano (OCDE, 2010). En el caso de España, por ejemplo, el análisis realizado recientemente por Martínez Celorrio y Marín Saldo (2012) evidencia que la educación determina en gran medida la posición social que ocupan las personas, aunque, al mismo tiempo, reduce la rigidez entre las clases sociales, redistribuyendo las oportunidades. De acuerdo con los datos de estos autores, “en la España actual el factor educación resulta determinante de los destinos de clase, pero matizado por el origen de clase, obteniendo un mejor enclasamiento y un mayor rendimiento de los títulos cuanto más alto sea el origen, y a la inversa. Una vez llegados hasta aquí, parece evidente que queda mucho por mejorar en el terreno de la igualdad de oportunidades educativas y en la reducción de la influencia de los orígenes de clase en los destinos" (ibídem: 169).

Estos mismos autores, en un análisis similar realizado para Cataluña, ponen de manifiesto que la educación constituye un filtro social central, en la medida en que determina, en mayor medida que el propio origen de clase, las posibilidades de ascenso social. Desde ese punto de vista, cabe pensar que la educación ha democratizado las oportunidades de ascenso social y es el principal reductor de la herencia social. Sin embargo, concluyen, “desde los años 90 se mantiene una desigualdad constante de oportunidades educativas entre los extremos sociales que perjudica la fluidez social” (ibídem).

Al analizar la relación entre los diferentes modelos y prácticas educativas y las pautas nacionales de movilidad social, se observa que, más allá del montante del gasto público en educación, lo relevante parece ser la eficiencia en la asignación de ese gasto, así como la calidad y el rendimiento del profesorado. Más concretamente, los datos de la OCDE apuntan a que la menor relación entre resultados académicos y entorno social de origen se produce en los países que incentivan el rendimiento de los profesionales de la enseñanza, en aquellos con sistemas impositivos más progresivos, en aquellos que no segmentan al alumnado en función de sus capacidades, y en aquellos que han apostado de forma más decidida por una atención infantil de calidad desde los primeros años de vida (OCDE, 2010).

\subsubsection{Movilidad social y relaciones parentofiliales: la importancia de la herencia cultural}

Diversos estudios han evidenciado que la pobreza infantil no se reduce al aspecto de los ingresos ${ }^{16}$.

${ }^{16} \mathrm{Si}$ bien resulta evidente el efecto de la carencia de recursos económicos, y por tanto, de las prestaciones de garantía de ingresos, en la superación de la pobreza infantil, es también necesario insistir en que la pobreza va más allá de la carencia de ingresos, y que muchos de los efectos negativos de la pobreza tienen que ver con las capacidades de los padres y las madres, con el contexto educativo y afectivo en el que se desarrollan sus primeros años y con los estí-
Del mismo modo, la reproducción social de la desigualdad no se relaciona sólo con una transmisión desigual de la riqueza heredada, ni con un acceso más o menos desigual a la educación, sino también -o sobre todo- con la transmisión del capital cultural familiar. "La renta familiar importa -explica EspingAndersen (2005)-, pero el capital cultural de los padres resulta mucho más decisivo, al menos en lo que se refiere al desarrollo cognitivo y el éxito escolar [...]. El dinero es importante, pero no es una condición suficiente para garantizar unas oportunidades vitales suficientes" ${ }^{17}$.

Corak (2013) ha puesto también de relieve la importancia de la educación y, más concretamente, de la inversión en capital humano, como factor explicativo de las mayores posibilidades de movilidad social. Para este autor, el incremento de la desigualdad reduce la movilidad social precisamente porque modifica de modo diferencial tanto las oportunidades como los incentivos de las familias para invertir en el capital humano de sus hijos: las familias con mayor capital humano, señala, invierten más en sus hijos/as. Esta mayor inversión puede estar influida por los recursos económicos y las mayores probabilidades de los progenitores de mayor renta para desarrollar las habilidades de sus hijos/as y ofrecerles experiencias enriquecedoras, sobre todo en la primera infancia. Por tanto, para Corak, las inversiones más relevantes no son necesariamente económicas, sino las relacionadas con el desarrollo de unas conductas, motivaciones y aspiraciones determinadas, así como con el establecimiento de vínculos relacionales que les serán de utilidad en la vida adulta ${ }^{18}$.

mulos socioafectivos que se reciben, entre otros factores. Desde esta perspectiva, y sin restar importancia al papel de las prestaciones económicas, debe también realzarse el papel de los servicios públicos -de atención infantil, educativos, culturales, de ocio o de salud-y la necesidad de desarrollar medidas, como los programas de parentalidad positiva, que permitan reducir el peso de la herencia social en las oportunidades vitales de la infancia, y ayudar a los padres y madres a cumplir con sus responsabilidades parentales (SIIS Centro de Documentación y Estudios, 2013).

17 Para este autor, la variable capital cultural -una variable construida a partir del número de libros en el hogar, la frecuencia en la que se habla de cuestiones culturales o la asistencia a actividades culturales- explica hasta dos veces más que la variable de renta la variación en las habilidades cognitivas de los/as niños/as.

${ }^{18}$ En ese sentido, Corak apunta dos datos de interés en torno a la desigual distribución de esta inversión en capital humano. Por una parte, cita una serie de estudios según los cuales mientras que el $20 \%$ más adinerado de la población estadounidense ha multiplicado por 2,5 en las últimas décadas el gasto que destinaba a productos y actividades que facilitan aprendizajes vitales adicionales a los que la escuela ofrece (clases particulares, equipamiento informático, viajes, libros, museos), en el caso de las familias del quintil más pobre el gasto apenas se han multiplicado por 1,5 , de tal forma que si en 1980 las familias más acomodadas gastaban en estos servicios 4,2 veces más que las familias menos acomodadas, en 2010 la diferencia era 6,7 veces mayor. Si bien se refiere a la realidad norteamericana, Corak sostiene que el crecimiento de las diferencias en la inversión monetaria y no monetaria que los diferentes grupos de renta hacen en sus hijos, en una época de creciente desigualdad, puede llevar a una creciente divergencia en lo que se refiere a las capacidades necesarias para obtener el éxito académico. Por otra parte, Corak recuerda que el apoyo de la familia de origen se produce en todas las fases vitales, y en las diferentes transiciones que se realizan hasta llegar al mercado de trabajo. Y en ese sentido, señala una serie de investigaciones según las cuales las conexiones familiares son cada vez más determinantes a la hora de conseguir un empleo, sobre todo si éste es de cierta calidad. En ese sentido, los datos de sus estudios apuntan a que las personas de rentas más ele- 


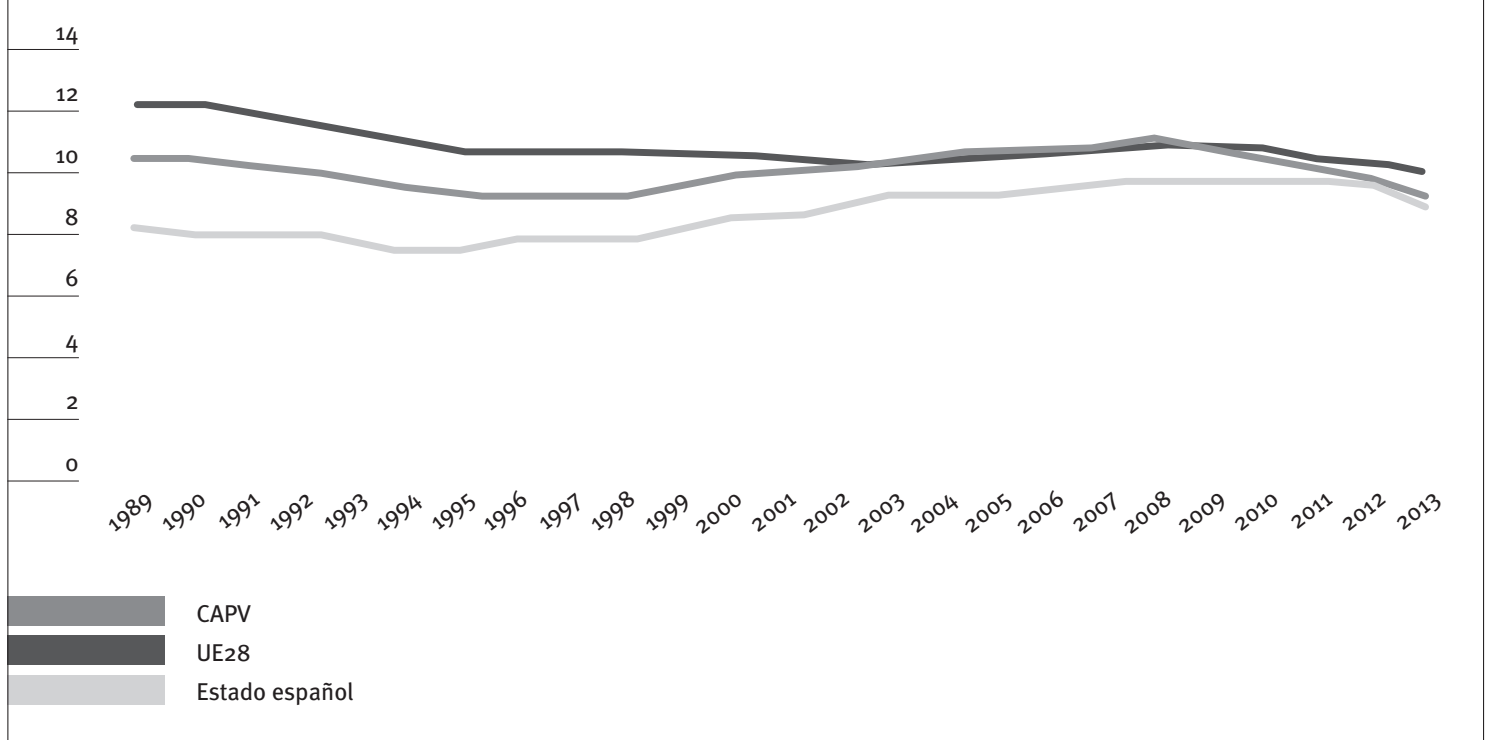

Fuente: Elaboración propia a partir de datos de Eurostat e INE.

Así pues, la herencia cultural que padres y madres transmiten a sus hijos/as, especialmente en los primeros años de vida, resulta mucho más relevante que las cualificaciones educativas o las diferencias de renta en lo que se refiere a las posibilidades de ascenso social (Esping-Andersen, 2005). Para este autor, una buena parte de las herencia intergeneracional de clase que observamos está mediada por el efecto parental en el desarrollo cognitivo de los/as niños/as, de tal forma que lo que ocurre en los hogares, antes incluso de acceder a la escolarización, requiere una atención especial. De ahí el énfasis en la educación infantil de calidad y en la inversión en los primeros años de vida -el enfoque de los 'años fundamentales’-, al que más tarde se hará referencia.

En este ámbito, parece desempeñar un papel importante la calidad de las relaciones parentofiliales y, más concretamente, el tiempo que padres y madres pasan con sus hijos/as. Así, de acuerdo con la OCDE, ese tiempo es una forma importante de inversión familiar que contribuye a la desigualdad intergeneracional. Pero el tiempo que los padres y madres pasan con sus hijos no se distribuye de forma equitativa, y los datos apuntan a que los padres y madres con mayor nivel educativo dedican más tiempo a estar con sus hijos/as, con lo que los/as niños/as de las clases favorecidas reciben una inversión en tiempo no sólo mayor, sino de mejor calidad (OCDE, 2009).

vadas tienen una posibilidad mucho mayor que el resto de la población de trabajar o haber trabajado en la misma empresa en la que trabaja o ha trabajado alguno de sus progenitores.

\subsection{La (re)emergencia del problema de la natalidad}

En el contexto actual de crisis económica, incremento de la desigualdad y estrangulamiento de las vías de movilidad social ascendente, vuelve a emerger en los países del sur de Europa el problema de la natalidad, que, si bien se mantenía en niveles reducidos, había ido aumentando en los años anteriores a la crisis.

Efectivamente, tanto en la CAPV como en el Estado español, tras los notables decrementos experimentados entre mediados de los setenta y mediados de los noventa, las tasas de natalidad fueron recuperándose, como se observa en el Gráfico 7, hasta alcanzar en 2008 las tasas más elevadas de los últimos veinte años. Sin embargo, en la CAPV y, más claramente, en el conjunto del Estado español, la tasa de natalidad ha vuelto a reducirse, llegando, en el caso vasco, a los niveles registrados en 2002. En el caso de la UE, el descenso en los años noventa fue menor, así como el incremento en la fase de crecimiento económico; con todo, si bien en menor proporción que en Euskadi y en España, la tasa de natalidad está cayendo también en la UE desde 2008.

Parece evidente que la caída en las tasas de natalidad está estrechamente ligada al ciclo económico y que está siendo más fuerte en los países del sur de Europa, los más afectados por la crisis. De acuerdo con Goldstein et al. (2013), la crisis económica y, más concretamente, el incremento en las tasas de desempleo, se relaciona directamente con la caída de la natalidad, de tal forma que se está revertiendo el incremento en las tasas de natalidad que se venía produciendo desde mediados de los noventa. De acuerdo con el estudio realizado, los grupos más afectados por este cambio son los menores de 25 
años, que tienden en mayor medida a retrasar la edad del primer embarazo. Los datos indican que un incremento de un $1 \%$ en la tasa de desempleo equivale a un descenso del o,1\% de la tasa de natalidad en el cómputo global de la UE, porcentaje que sube al $0,3 \%$ en los países del sur de Europa.

Parece, por tanto, evidente que el entorno económico $y$, particularmente, las tasas de desempleo se relacionan con las tasas de natalidad y que, por tanto, la intervención sobre el mercado de trabajo permitiría revertir nuevamente esta tendencia al descenso de las tasas de natalidad. En ese sentido, los trabajos más recientes de Esping-Andersen et al. (2013) en relación a la natalidad en Europa ponen de manifiesto datos de interés sobre las políticas y los contextos que parecen facilitar tasas de fecundidad más elevadas. Los resultados obtenidos apuntan a dos cuestiones básicas: en primer lugar, son fundamentales los cambios en las relaciones de género a fin de garantizar una mayor igualdad -no sólo en las parejas y las familias, sino también en la esfera pública-; y, en segundo lugar, las condiciones que regulan las relaciones laborales y el mercado de trabajo parecen ser mucho más importantes de lo que se había pensado hasta ahora. En efecto, a juicio de estos autores, "el contexto laboral desempeña un papel de primer orden para promover o frenar la natalidad. Las tasas de desempleo persistentemente elevadas de España, junto con una inseguridad laboral generalizada -sobre todo entre los trabajadores jóvenes-, constituyen importantes barreras para la formación de familias". Dicho efecto es especialmente negativo para las mujeres con mayor nivel educativo, debido a que tanto el paro como la inseguridad laboral retrasan la transición del sistema educativo a un empleo estable, lo que a su vez retrasa la independencia económica y la decisión de tener hijos.

\section{Nuevos paradigmas y orientaciones para las políticas familiares en Europa}

\subsection{El paradigma de la inversión social}

Como se ha señalado en otros trabajos (SIIS Centro de Documentación y Estudios, 2012a), desde mediados de los años noventa y, con más claridad, a partir de los primeros años del siglo XXI, se ha ido desarrollando, sobre todo en Europa, un enfoque que, para muchos, implica un cambio de paradigma en la definición de las políticas de bienestar social y que, como se señala más adelante, trae aparejado un cambio fundamental en el papel de las políticas de apoyo a las familias con hijos/as, a los que se otorga una nueva o mayor centralidad en el conjunto de las políticas de protección social. Este nuevo paradigma supone -entre otros elementos- una nueva forma de concebir la intervención pública respecto a la infancia, en la medida en que el bienestar y el óptimo desarrollo cognitivo y emocional de los niños y niñas se considera un factor esencial de cara a la cohesión, a largo plazo, del conjunto de la sociedad. Desde ese punto de vista, la inversión en la infancia, el desarrollo de las políticas de apoyo a las familias, la provisión de cuidados infantiles de calidad y, por extensión, la lucha contra la pobreza infantil se configuran como ejes básicos del llamado modelo de inversión social.

La principal característica de este enfoque es, tal y como han señalado Morel, Palier y Palme (2012), el cambio de énfasis desde unas políticas orientadas a la reparación a otras orientadas a la preparación (preparing rather than repairing). De acuerdo con estos autores, el enfoque de la inversión social se basa en políticas que buscan tanto el desarrollo del capital humano (cuidados infantiles y educación precoz, formación a lo largo de toda la vida) y el aprovechamiento eficiente de ese capital (mediante políticas que favorecen la combinación de flexibilidad y seguridad), como la consecución de mayores cotas de inclusión social, fundamentalmente mediante el acceso al mercado de trabajo de grupos tradicionalmente excluidos de él ${ }^{19}$. En cualquier caso, un elemento distintivo básico de este enfoque es la idea de que las políticas sociales deben considerarse un elemento productivo, esencial para el desarrollo económico y el crecimiento del empleo, lo que constituye un cambio radical con la consideración de las políticas sociales como una carga económica y un obstáculo al crecimiento.

Como ha señalado Gøsta Esping-Andersen (2002), el concepto de política social productiva que subyace al enfoque del Estado social inversor aspira a reconciliar los objetivos de equidad y eficiencia, a menudo considerados opuestos o antagónicos. Según este autor, sin embargo, la equidad no es sólo compatible con la eficiencia, sino, realmente, un requisito para su optimización: "Una capacidad adquisitiva distribuida de forma más igualitaria es una precondición para el rendimiento macroeconómico; las políticas de apoyo a las familias son una inversión en el capital humano del futuro; la igualación de los recursos, como la salud o la educación, es la base de una productividad laboral óptima”. En efecto, la perspectiva de la política social productiva parece capaz de resolver la tensión entre la seguridad individual y la solidaridad social, por un lado, y el interés colectivo de la eficiencia económica y la participación productiva individual, por otro, reconciliando de esa forma la lógica de los derechos y la lógica de las responsabilidades.

Si hay un ámbito de las políticas sociales en el que el cambio de enfoque que supone Estado social inversor incide de forma clara y determinante, es el de las políticas de apoyo a las familias, en la medida en que ganan una centralidad de la que hasta el momento han carecido en la mayor parte de los países. Invertir en el bienestar de la infancia y, por extensión, de las familias constituye el eje del Estado social inversor

${ }_{19}$ Desde ese punto de vista, puede pensarse que este enfoque se relaciona de forma directa con el paradigma de la inclusión activa desarrollado, con enfoques y acentos distintos, en la mayor parte de los países de la UE en el ámbito de las prestaciones de garantía de ingresos (SIIS Centro de Documentación y Estudios, 2012b). 
a partir de la defensa de una estrategia de inversión social basada en la infancia (Esping-Andersen, 2002). La base de esa estrategia radica en la idea, ya apuntada con anterioridad, de que los mecanismos que afectan a la desigualdad y la exclusión operan fundamentalmente durante la primera infancia y se concentran sobre todo en el seno de la familia. Para los defensores de este enfoque, cualquier política eficaz de redistribución, igualdad de oportunidades y lucha contra la exclusión debe, por tanto, centrarse, de modo prioritario, en esa época y en ese ámbito.

Efectivamente, como ha señalado Morgan (2012), las políticas de conciliación de la vida familiar y laboral son uno de los ejes centrales del enfoque del Estado social inversor. Los programas de calidad orientados a la educación precoz y a los cuidados infantiles invierten tanto en el desarrollo cognitivo de los/as niños/as como en las capacidades laborales de sus madres, permitiéndolas acceder al mercado remunerado. El empleo de las madres incrementa los ingresos familiares, reduciendo la pobreza infantil y sus efectos a largo plazo. Las bajas parentales y la flexibilización del tiempo de trabajo promueven la inserción laboral de las madres, al tiempo que permiten que los/as niños/as se beneficien de periodos de cuidado parental. Finalmente, los servicios de cuidado y educación infantil constituyen un nicho de empleo para las mujeres.

En el ámbito de las políticas familiares y de infancia, el Estado social inversor tiene entre sus principales preocupaciones permitir la conciliación de la vida familiar y la vida laboral, facilitando la incorporación de la mujer al mercado de trabajo y adaptando las políticas sociales a la progresiva desaparición del modelo en el que sólo el hombre trabajaba y sólo la mujer cuidaba (male breadwiner model). Al mismo tiempo, busca favorecer la igualdad de oportunidades en la infancia, rompiendo el ciclo de transmisión intergeneracional de la pobreza al que antes se ha hecho referencia, de forma que todos los niños y niñas puedan desarrollar el capital humano imprescindible en la economía del conocimiento. Esto sólo puede lograrse mediante medidas de apoyo a las familias, y el desarrollo de sistemas de educación y cuidado infantil de alta calidad y de amplia cobertura.

La apuesta por el Estado social inversor no es, en cualquier caso y únicamente, una propuesta académica. Al contrario, está siendo crecientemente adoptada como una de las bases filosóficas y conceptuales de las políticas sociales que impulsa la UE, que está articulando todas sus iniciativas políticas y de financiación en función de este enfoque ${ }^{20}$.

20 "En 2013, la Comisión Europea presentó un paquete de inversión social para el crecimiento y la cohesión que contribuirá a que la UE alcance sus objetivos de crecimiento integrador en 2020. En él, se establece un marco de actuación y se proponen medidas concretas para la UE y los países miembros, acompañadas de orientaciones en cuanto a la utilización de los fondos de la UE para apoyar las reformas. El paquete de medidas aborda problemas como la superación del círculo vicioso de las desigualdades de la infancia, el envejecimiento demográfico, la inclusión activa de las personas excluidas del mercado laboral, la situación de las personas sin hogar, los servicios

\subsection{La importancia de la intervención precoz: los} años fundamentales

A la hora de analizar el paradigma de la inversión social, ya se ha hecho referencia al papel que sus promotores conceden a la atención infantil de calidad y a la intervención precoz en la infancia, a partir de la idea de que hoy día las principales desigualdades se relacionan con la acumulación del capital humano y de que, en una gran medida, tales desigualdades aparecen, y se fijan, en los primeros años de vida. En ese sentido, son cada vez más numerosos y concluyentes los estudios que ligan los primeros años de vida y la intervención precoz con el potencial de desarrollo a lo largo de toda la vida, bajo un paradigma común que cabe englobar en el concepto genérico de los 'años fundamentales' (foundation years), en el sentido de que se trata de la fase en la que se colocan los fundamentos de toda la trayectoria vital posterior.

Este énfasis en los años fundamentales se basa tanto en los avances de la sociología y de la pedagogía como, sobre todo, en los resultados que arrojan los estudios neurológicos. De acuerdo con Adamson (2008), los avances en la investigación neurocientífica están evidenciando que "las interacciones tempranas del niño con otras personas, máxime con la familia y los cuidadores, establecen las pautas de las conexiones neuronales y los equilibrios químicos que influyen profundamente en lo que nos convertiremos, en lo que seremos capaces de hacer y en cómo reaccionaremos ante el mundo que nos rodea. Por lo que respecta al potencial de la herencia genética, la experiencia temprana es la que conforma la arquitectura del cerebro humano, sentando las bases para el desarrollo futuro". Adamson cita un informe del Consejo Científico Nacional de Estados Unidos según el cual "todos los aspectos del capital humano adulto, desde las aptitudes de la fuerza de trabajo hasta una conducta lícita y cooperativa, se basan en las capacidades que se desarrollan durante la infancia, empezando por el nacimiento". En otras palabras, añade, "la neurociencia empieza a confirmar y explicar el engranaje de lo que la ciencia social y la experiencia común vienen manteniendo desde hace tiempo: que unas relaciones afectuosas, estables, seguras, estimulantes y gratificantes con la familia y los cuidadores durante los primeros meses y años de vida son esenciales para casi todos los aspectos del desarrollo de un niño".

Heckman (2006) ha resumido con claridad la importancia que la intervención precoz tiene en las perspectivas vitales de los/as niños/as:

En décadas de investigaciones independientes en los ámbitos de la economía, la neurociencia y el desarrollo psicológico han surgido cuatro

sociales de interés general, los cuidados de larga duración y la salud. La inversión social es uno de los cometidos de las políticas sociales, junto con la protección social y estabilización de la economía” (Comisión Europea, 2014: 12). 
conceptos básicos que resultan importantes para diseñar políticas sociales sólidas dirigidas a la primera infancia. En primer lugar, la arquitectura del cerebro y el proceso de formación de aptitudes se ven influidos por la interacción entre la genética y la experiencia individual. En segundo lugar, el dominio de aptitudes esenciales para el éxito económico y el desarrollo de sus vías neuronales subyacentes sigue unas normas jerárquicas. Los logros posteriores se sustentan en bases que se establecen con anterioridad. En tercer lugar, las competencias cognitivas, lingüísticas, sociales y emocionales son interdependientes; todas se ven poderosamente influidas por las experiencias del niño en desarrollo y todas contribuyen al éxito en la sociedad en su conjunto. En cuarto lugar, aunque la adaptación continúa a lo largo de la vida, las capacidades humanas se forman en una secuencia previsible de períodos sensibles, durante los cuales el desarrollo de circuitos neuronales específicos y las conductas que median son fundamentalmente plásticas y, por tanto, receptivas al máximo a las influencias del entorno.

Este autor es también uno de los investigadores que con más rigor han evidenciado la relación de costeefectividad que se deriva de una intervención precoz de calidad. A su juicio, la neurociencia y la psicología experimental han demostrado que los primeros años de edad son críticos para el aprendizaje, tanto desde el punto de vista cognitivo como no cognitivo. El aprendizaje, señala, es un proceso dinámico en el que los aprendizajes precoces refuerzan los posteriores. Las implicaciones del aprendizaje precoz para el desarrollo del capital humano son claras, señala Heckman: el momento óptimo para una intervención productiva, el momento óptimo para invertir, es cuando los niños y niñas son muy pequeños. Así, los datos de este autor ponen de manifiesto que las intervenciones resultan tanto más rentables o costeefectivas cuanto antes se desarrollen.

En diciembre de 2010, el Gobierno británico publicó un influyente informe sobre la relación entre estos años fundamentales y la pobreza infantil. Bajo el título de Los años fundamentales: prevenir que los niños pobres se conviertan en adultos pobres, Field (2010) señala que existen evidencias de que las oportunidades vitales se definen muy particularmente en función del desarrollo de los niños y niñas durante sus cinco primeros años de vida. Desde su óptica, el contexto familiar, la educación y las habilidades parentales y las oportunidades de aprendizaje y desarrollo en estos años cruciales influyen, en conjunto, más que el dinero a la hora de definir las oportunidades en la vida adulta. Lo que más influye es, por tanto, para Field, un embarazo saludable, una buena salud mental materna, un vínculo sano con el niño o la niña, el amor y la responsabilidad de los progenitores, junto con límites claros y oportunidades para el adecuado desarrollo cognitivo, lingüístico, social y emocional de los/as niños/as. Para ello se precisan servicios adecuados de salud prenatal e infantil, y buenos servicios de atención infantil. Las intervenciones más tardías dirigidas a los niños con peores resultados pueden ser efectivas, reconoce Field, "pero en general la forma más eficaz y coste-efectiva de ayudar a las familias consiste en intervenir en los primeros años de vida de sus hijos/as".

El acceso de los niños a las guarderías y a centros prescolares de gran calidad debe, pues, formar parte de una política verdaderamente eficaz en favor de la igualdad de oportunidades si se tiene en cuenta, como señala Esping-Andersen, que las bases del aprendizaje, así como el origen principal de las desigualdades, se remontan al periodo prescolar. En la medida en que el acceso al cuidado de los niños condiciona también el trabajo de las madres -que, a su vez, es portador de efectos económicos positivos-, unas medidas que favoreciesen el cuidado de los/as niños/as serían un perfecto ejemplo de política doblemente ganadora (Esping-Andersen y Palier, 2010). En el mismo sentido, Waldfogel (2005) sostiene que las políticas centradas en la atención precoz fomentan la movilidad social y el bienestar de los/as niños/as, al tiempo que permiten alcanzar otros objetivos, como la inclusión social, la reducción de la pobreza, el empleo parental, la capacidad de elección de los progenitores o la igualdad de género.

La cuestión de la calidad es, desde ese punto de vista, esencial. Un estudio realizado por Esping Andersen et al. (2012) en el que se relaciona el efecto de la atención infantil recibida a la edad de 3 años con los resultados cognitivos que se registran a los 11, indica que, en Dinamarca, la recepción de cuidados infantiles se relaciona positivamente con mejores resultados, sobre todo entre los niños de entornos socioeconómicos más bajos. En Estados Unidos, por el contrario, beneficiarse de esos cuidados sí parece marcar diferencias en el momento de entrar en la educación obligatoria, pero tal efecto desaparece a la edad de 11 años, especialmente entre los/as niños/as de entornos desaventajados. Para los autores, la evidencia científica disponible pone de relieve que los programas de atención infantil ofrecen resultados positivos si son de alta calidad y, de hecho, las notables diferencias en el efecto de la atención infantil que se detectan entre Dinamarca y Estados Unidos se deben, precisamente, al distinto nivel de calidad de ambos sistemas.

En todo caso, optar por la intervención precoz implica un cierto desplazamiento del propio gasto que se destina a la infancia, que en la actualidad se encuentra muy concentrado en la etapa de la escuela obligatoria. Los datos que al respecto ofrece la OCDE (2009) indican que, en la mayoría de los países occidentales, la mayor parte del gasto se concentra en la última etapa de la infancia. Para Adema (2012), sin embargo, centrar el gasto en las fases más precoces contribuye a la equidad, en la medida en que reduce los gastos que a corto, medio y largo plazo se derivan de una escasa atención al desarrollo infantil durante los primeros años de vida. 
3.3. El bienestar basado en el patrimonio, la pre-distribución y la democracia de propietarios

Otra tendencia de interés -relacionada con la desigualdad en la transmisión del patrimonio económico y cultural de las familias y a la que antes se ha hecho referencia- es el llamado bienestar basado en el patrimonio o asset based welfare. Como se ha señalado en otros trabajos (Zalakain, 2013), si el paradigma de la inversión social implica una recapitalización del conjunto de la población -y, en especial, de la infancia- desde el punto de vista del capital humano, enfoques como el del llamado asset based welfare o bienestar basado en el patrimonio enfatizan los beneficios que la generación de un capital o patrimonio económico puede tener para las familias pobres y para la infancia en general.

Si bien no se trata de un enfoque estrictamente novedoso -las principales iniciativas se remontan, al menos, a finales de los noventa-, se trata de un cambio de enfoque que entronca, claramente, con algunos de los paradigmas -como el de la inversión social y la centralidad de la primera infancia- a los que se ha hecho ya referencia, y que, por otra parte, se plantea como herramienta para prevenir la reproducción intergeneracional de la desigualdad, a la que también se ha aludido previamente.

Para los partidarios de este enfoque, disponer de un capital económico, inmobiliario o de cualquier otro tipo constituye una de las mejores defensas contra la pobreza y una de las mejores herramientas para salir de ella, sobre todo a la luz de las diferencias en la dotación inicial de capital económico y humano anteriormente reseñadas. Para Le Grand (2007), las personas que disponen de cierto patrimonio tienen mejor salud, tasas más bajas de mortalidad, mayor estabilidad matrimonial, menos violencia doméstica, mejores resultados escolares y más ahorros. A estas razones se añaden otras de tipo psicológico y conductual, de acuerdo con las cuales la disposición de un cierto patrimonio económico provoca un sentimiento de seguridad, autoestima, control y de confianza en las propias posibilidades. Uno de los iniciales defensores de este enfoque, Sherraden, autor de Assets and the Poor, mantiene en ese sentido que "los ingresos sólo permiten mantener el consumo, mientras que el patrimonio cambia la forma en que las personas interactúan con el mundo. Con el patrimonio, las personas empiezan a pensar a largo plazo y a marcase objetivos a largo plazo". A partir de esas premisas, los defensores de estas políticas coinciden en que ayudar, desde las instituciones públicas, a disponer de un capital para comprar un coche o una casa, iniciar un empleo por cuenta propia, pagar unos estudios o resolver una situación de emergencia constituye una forma innovadora e inteligente de activación de las políticas sociales ${ }^{21}$.

${ }^{21}$ Este tipo de políticas tienen también, sin embargo, sus críticos, que mantienen fundamentalmente tres argumentos. El primero es el de la posibilidad de que estas medidas sean vistas como alternativa, y no como complemento, a las actuales prestaciones económicas
Una plasmación concreta de este enfoque son las llamadas cuentas de desarrollo infantil (child development accounts) desarrollados en países como Estados Unidos, Canadá, Reino Unido, Singapur o Corea. Consisten, en general, en dotar a los/as niños/as o jóvenes de sumas relativamente importantes por parte de la Administración, que se mantienen, revalorizándose, en cuentas de ahorro hasta que se pueden dedicar al fin previsto o hasta que se cumple la mayoría de edad. En algunos casos, las aportaciones públicas se complementan con aportaciones privadas, siendo en general la aportación pública proporcional a la de las familias - para determinadas familias y con determinados topes-, al objeto de fomentar la inversión de las familias en estas cuentas.

Si bien no puede decirse que en Europa este enfoque se haya extendido mucho -el Reino Unido fue el país que más avanzó al respecto con el Gobierno laborista, aunque el programa fue eliminado por el Gobierno conservador-, la construcción de una democracia basada en un reparto más equitativo del patrimonio se ha planteado también en Europa como una respuesta a la crisis y al crecimiento de la desigualdad $^{22}$. En ese sentido, la idea del asset based welfare se vincula claramente con los conceptos de predistribución y democracia de propietarios que están empezando a defender (o a recuperar) los partidos socialdemócratas, especialmente anglosajones.

periódicas. La crítica es más que razonable si se tiene en cuenta que el desarrollo de estas iniciativas en Estados Unidos -a través, por ejemplo, de las llamadas cuentas individuales de desarrollo- se produce a raíz de la reforma del sistema de bienestar social que redujo las cuantías y limitó las condiciones de acceso al welfare de aquel país. La segunda de las críticas se refiere al coste de oportunidad de las medidas: existiendo todavía necesidades acuciantes en materia de servicios sociales y de políticas de garantía de ingresos, con cuantías y coberturas muy limitadas, ¿no sería mejor desarrollar plenamente estas políticas para después preocuparse del ahorro o de la acumulación de capital? Desde ese punto de vista, estas medidas se consideran además un parche que evita adoptar medidas más radicales y necesarias en la lucha contra la exclusión social. La última crítica se refiere a la capacidad de ahorro de las familias con menos recursos: ¿qué puede ahorrar una familia que carece de los medios económicos para cubrir sus necesidades básicas? Las experiencias desarrolladas hasta la fecha parecen evidenciar, en ese sentido, sin embargo, que las familias más pobres -aunque sea poco- son capaces de ahorrar a lo largo del tiempo.

${ }^{22}$ En los últimos años se han planteado diversas propuestas más o menos concretas al respecto. Le Grand y Nissan (2000) proponen un sistema de este tipo en el que cada persona recibiera 10.000 libras al cumplir su mayoría de edad, financiadas mediante un incremento del impuesto de sucesiones. En parecidos términos, Prabhakar, Rowlinson y White (2008) han planteado la posibilidad de destinar la recaudación del impuesto de sucesiones -que, como antes se ha señalado, proponen mantener y reforzar- a cuentas de desarrollo infantil similares a las descritas, vinculando así este impuesto a las estrategias de igualdad de oportunidades que preconiza el paradigma de la inversión social. Una propuesta similar, más reciente, es la de Williamson (2012), que propone, mediante la tributación permanente de las herencias y los grandes patrimonios, crear una serie de fondos para garantizar a toda la población el acceso a tres tipos de capital -inmobiliario, efectivo y productivo- en forma de acciones. El objetivo de esta estrategia sería -en un plazo de 20030 añosgarantizar que todas las familias tuvieran acceso a bienes por valor de al menos 100.000 dólares, con lo que se crearía una sociedad en la que toda la población tendría acceso a un patrimonio sustancial (O’Neill y Williamson, 2014). 
El concepto de predistribución se relaciona con la idea de que la prevención de la desigualdad debe centrarse preferentemente en una adecuada distribución primaria de las rentas y el capital-económico y humano-, y no tanto en la redistribución una vez que la desigualdad se ha producido, mediante impuestos o prestaciones económicas. Este enfoque implica un cambio de énfasis de la renta al patrimonio ('duro' y ‘blando', es decir, económico, pero también cultural y relacional). Así, para Ussher (2012), “la predistribución requiere, en primer lugar, de un plan para extender la riqueza inmobiliaria de forma más igualitaria y para proteger a las personas frente a la inseguridad económica. El segundo paso sería adoptar un enfoque basado en el patrimonio para el conjunto de las políticas sociales [...]. Además, la agenda de la predistribución ha de orientarse a las capacidades personales. El capital humano es el patrimonio más importante que una persona puede poseer". La conexión entre este enfoque y el de la inversión social, y su vinculación con la cuestión de la movilidad social, a la que antes se ha hecho referencia, es innegable.

La idea de la predistribución se deriva, a su vez, del concepto de democracia de propietarios de John Rawls ${ }^{23}$ y de otros pensadores clásicos de izquierda, como James Meade ${ }^{24}$. Como explica Jahel Queralt (2012):

El Estado del bienestar acepta una distribución desigual del capital real y humano, y utiliza un sistema de impuestos y transferencias para corregir ex post las consecuencias que dichas desigualdades tienen en el mercado. La democracia de propietarios, en cambio, pone menos énfasis en la distribución de las ganancias mercantiles e incide directamente en la distribución del capital con el que los individuos participan en el mercado para lograr más igualdad ex ante. Los mecanismos ex post mitigan la gran desigualdad que emergería en un sistema laissez faire, pero siguen generando desigualdades importantes [...]. Los mecanismos ex ante evitan la concentración de capital y, de este modo, hacen que las desigualdades generadas por el mercado sean, de entrada, menores. En su concisa crítica al Estado de bienestar, Rawls señala que, incluso en su mejor versión, este sis-

${ }_{23}$ "Rawls no ofrece grandes concreciones institucionales cuando habla de democracia de propietarios, tampoco es ésa, piensa, la labor del filósofo político, pero el ideal -de clara raigambre jeffersonianaes claro: la propiedad es una institución central, y la única forma de acercarnos a su ideal de justicia distributiva es ciñendo al máximo los efectos, potencialmente devastadores, de la propiedad -mediante un amplio abanico de mecanismos redistributivos que impidan su concentración privada- sobre la igualdad de libertad, de oportunidades, de ingresos y riqueza, y de las condiciones que hacen posible la dignidad humana” (De Francisco y Raventós, 2003).

24 "Meade [...] es el autor en quien el propio Rawls ancla su defensa de la democracia de propietarios. Formado en política, filosofía y economía, Meade osciló políticamente entre el laborismo y el socialismo, en los años 6o. Desde un lugar prominente en la vida pública inglesa, defendió un rol activo del Estado en la redistribución del ingreso y la riqueza, impuestos progresivos y un ingreso básico para todos (basic income). Pero el eje de su propuesta estuvo en asegurar un distribución mucho más igualitaria de la propiedad, por razones afines a las que utilizara el republicanismo" (Gargarella, 2012). tema es inadecuado para satisfacer plenamente su concepción de la justicia.

\subsection{El recurso a las herramientas fiscales en el marco de las políticas familiares}

El recurso a las herramientas fiscales en el marco de las políticas familiares es una de las tendencias que en mayor medida está modificando las formas de provisión de las ayudas a las familias. Como señalan Ferrarini, Nelson y Höög (2012):

Los Estados de bienestar están siendo objeto de una sutil y en ocasiones inadvertida transformación: la fiscalización de las prestaciones sociales. Este cambio es especialmente notable en el ámbito de las políticas familiares, donde en los últimos años se han introducido una serie de créditos o deducciones fiscales infantiles que han modificado tanto el nivel como la composición de las políticas familiares.

Ya se ha señalado en qué medida el sistema de protección a las familias en Euskadi se basa en desgravaciones fiscales que, por una parte, reducen de forma considerable la presión fiscal de las familias de rentas medias y altas, pero de las que, por otra, no se benefician, en igual medida al menos, las unidades familiares con ingresos muy bajos o sin ingresos. Por otra parte, en anteriores trabajos (SIIS Centro de Documentación y Estudios, 2013) se ha descrito cómo en muchos países se está produciendo una mayor integración de las políticas fiscales y sociales y que, en ese contexto, las desgravaciones fiscales reembolsables (los denominados tax credits) pueden resultar una herramienta de interés en la CAPV, en la medida en que permiten un acceso más normalizado a las prestaciones familiares o de garantía de ingresos, y en la medida en que, al facilitar que todas las familias, independientemente de su renta, se beneficien de las deducciones actuales, facilitan una mayor progresividad del sistema fiscal.

En líneas generales, estas deducciones se diferencian del resto de las deducciones fiscales en el hecho de que no están limitadas a la deuda tributaria del contribuyente: la deducción reembolsable reduce la deuda con Hacienda, hasta cero, en su caso, como ocurre con el resto de las deducciones; pero si la deducción es superior a la cuota líquida, esa diferencia se convierte en una transferencia neta que se le abona al contribuyente, en forma de impuesto negativo. En algunos de los sistemas aplicados en nuestro entorno, la compensación tiene, hasta un nivel salarial determinado, un carácter progresivo (la deducción crece a medida que aumentan los ingresos salariales) y decreciente a partir de ese umbral (decrece a medida que los ingresos propios aumentan), de forma que, superado el máximo de ingresos salariales fijado, el derecho a la compensación desaparece. Uno de los objetivos básicos de este tipo de deducciones reembolsables -junto con la protección de los trabajadores de bajos salarios, y la incentivación del acceso al empleo 
de estos trabajadores o de los perceptores de prestaciones de garantía de ingresos- es precisamente el de desarrollar las políticas de apoyo a las familias con hijos e hijas, incrementando además la progresividad del sistema fiscal.

La aplicación en el marco de la CAPV de prestaciones fiscales de este tipo podría tener un potencial importante si se tiene en cuenta, entre otras razones, el éxito que han tenido en otros países en lo que se refiere a la reducción de la pobreza infantil. En ese sentido, el informe del SIIS Centro de Documentación y Estudios al que se ha hecho referencia (2013: 50) señala que estas desgravaciones fiscales podrían jugar un cierto papel en lo concerniente a: "impulsar las políticas de apoyo a las familias, claramente infradesarrolladas en Euskadi en relación a la mayor parte de los países de Europa; prevenir y reducir la problemática de la pobreza infantil, que, si bien es en Euskadi inferior a la que se registra en la UE, ha crecido de forma notable a consecuencia de la crisis y es sistemáticamente mayor que la correspondiente al conjunto de la población; y, sobre todo, posibilitar una orientación más pro-infantil del conjunto del sistema de protección social vasco, orientándolo en mayor medida hacia las familias con hijos/as y las personas jóvenes".

Los tax credits forman parte de un movimiento más amplio orientado a la integración de impuestos y prestaciones sociales. Para Hermida y Noguera (2013), "durante la última década y media es posible identificar una tendencia de reforma de los sistemas fiscales y de protección social en varios países de la Unión Europea, que persigue una mayor integración $y$ coherencia entre los impuestos personales y las prestaciones sociales en dinero. Dichas reformas se inspiran parcialmente en los créditos fiscales que ya desde la década de 1970 se introdujeron en los Estados Unidos (y posteriormente en otros países anglosajones, como Australia, Canadá o Nueva Zelanda)". Tal y como explican estos autores, las políticas de integración de impuestos y prestaciones son aquellas que buscan o mantienen la consistencia en el continuo impuestos-prestaciones, estableciendo un 'tramo negativo' de impuesto (esto es, permitiendo que la deducción o desgravación fiscal pueda convertirse en prestación directa) y, a la inversa, permitiendo cobrar una prestación como deducción o desgravación fiscal si se tiene renta imponible. Hermida y Noguera consideran que "las propuestas de IIP [integración de impuestos y prestaciones] pueden resultar especialmente idóneas en un contexto socioeconómico cambiante como el actual, marcado por la contención presupuestaria y la creciente flexibilidad del mercado de trabajo y de las trayectorias vitales [...]. En definitiva, no es descabellado afirmar que un paquete de medidas de IIP inteligentemente diseñado y gestionado podría ayudar a aminorar algunos de los principales problemas de adaptación del actual sistema de protección social y del sistema fiscal al contexto socioeconómico previsible en los próximos años" (ibídem).
El protagonismo de este tipo de herramientas fiscales no ha dejado de crecer en los últimos años en el ámbito de las políticas familiares, tal y como ponen de manifiesto Ferrarini, Nelson y Höög (2013). Estos autores dividen las ayudas familiares en seis tipos. Por una parte, las prestaciones sociales: universales (es decir, no vinculadas a la renta de la familia), vinculadas al empleo, y selectivas o condicionadas al nivel de renta. Por otra, las deducciones, también de tres tipos: las deducciones clásicas, la reducción en las cotizaciones a la Seguridad Social, y los créditos fiscales reembolsables o tax credits, a los que se ha hecho referencia. En su trabajo, analizan en qué sentido han evolucionado las políticas familiares de dieciocho países de la OCDE y ponen de relieve que son esos últimos los que en mayor medida han crecido en los últimos años: si en 1960 se usaban en un solo país (Dinamarca), en 2005 se utilizaban en trece. De hecho, es la expansión de este tipo de créditos a partir sobre todo de 1995 -con el EITC norteamericano y el Child Tax Credit británico a la cabeza- lo que explica el incremento en la cobertura de las prestaciones familiares que, en su ausencia, habrían ido reduciendo su capacidad de protección.

No todos los países han optado, sin embargo, por este modelo. Ferrarini, Nelson y Höög señalan que mientras que los países nórdicos han mantenido una trayectoria universalista mediante la utilización de prestaciones familiares universales, el recurso a las herramientas fiscales se ha utilizado fundamentalmente en Australia, Canadá, Alemania, Nueva Zelanda y los Estados Unidos. El resto de los países analizados en su estudio -Austria, Bélgica, Francia, Italia, Japón, Países Bajos, Suiza y Reino Unido ${ }^{25}$ habrían seguido una trayectoria mixta, en la que se han combinado ambos tipos de enfoque.

La utilización de estas herramientas comporta, en función de su diseño, ciertos riesgos. Para estos autores, el creciente recurso a los tax credits implica, por una parte, una erosión de las políticas universales, en la medida en que, en la mayor parte de los casos, estas deducciones están condicionadas al nivel de renta familiar, con lo que se contribuye a la generación de modelos más selectivos. También implican una reducción de las cuantías recibidas por las familias, dado que, en general, las cuantías de los créditos fiscales -salvo en Australia y Alemania- son más bajas que las correspondientes a las ayudas directas. Desde este punto de vista, los autores señalan que los países que han seguido una trayectoria mixta tienden a ofrecer a las familias un nivel de protección mayor que aquellos que han apostado únicamente por las herramientas fiscales. A su juicio, por tanto, el recurso a los sistemas fiscales esconde un regreso a los criterios de selectividad que se consideraban superados.

${ }^{25}$ El caso británico es muy ilustrativo. En 1995, la prestación universal por hijo/a suponía en torno al $10 \%$ del salario neto y era la única ayuda existente. Sin rebajar el nivel de esta ayuda, en esa época se introdujo un crédito fiscal que elevó por encima del $15 \%$ la capacidad de protección del sistema. 
También en el Estado español se está avanzando en el desarrollo de estas prestaciones. Así, la última reforma fiscal del Gobierno plantea extender a las familias numerosas la deducción de 1.200 euros anuales por hijo/a a cargo (hasta un límite de 4.800 euros), que en la actualidad se aplica únicamente a las madres de niños/as menores de tres años ocupadas en el mercado laboral y que tiene un carácter de crédito fiscal reembolsable: los contribuyentes del IRPF con derecho a esta deducción pueden solicitar su abono anticipado, a razón de 100 euros mensuales por hijo/a, y puede percibirse como un ingreso neto si la deducción supera la cuota líquida del o la contribuyente.

\subsection{Políticas de apoyo a la parentalidad en Europa}

Si bien, por cuestiones de espacio, no es posible analizar aquí en detalle el enfoque de la parentalidad positiva, interesa señalar su emergencia por dos razones: por una parte, porque se corresponde con algunos de los elementos que se han apuntado previamente, como la inversión social en la infancia, o la importancia de las relaciones parentofiliales y de la transmisión intrafamiliar del capital humano; por otra, porque pone de manifiesto que existe un arsenal de políticas familiares que va más allá de las que habitualmente se analizan (prestaciones económicas, servicios de atención infantil, medidas para la conciliación laboral) y que están relacionadas con la intervención socioeducativa.

De acuerdo con la Comisión Europea (2011), desde los años noventa se han desarrollado de forma notable en Europa programas de apoyo a la parentalidad, que, si bien presentan características y enfoques muy diversos, coinciden en el objetivo básico de apoyar a los padres y las madres en el ejercicio de su función, facilitando la generación de un ambiente familiar positivo: el apoyo parental, señala este informe, se define como la provisión de servicios dirigidos a la mejora de las habilidades y las prácticas parentales, de cara a satisfacer las necesidades físicas, emocionales y sociales de niños y niñas. Para Daly (2012), “el apoyo a la parentalidad se refiere a las medidas o servicios de información, apoyo, educación, formación o asesoramiento que se centran en la forma en la que padres y madres conciben y llevan a la práctica su función parental". Este tipo de programas se han considerado como una palanca útil para mejorar el rendimiento escolar y prevenir el desarrollo de conductas problemáticas, y se consideran -cuando se dirigen a las familias más desfavorecidas- una herramienta adecuada para prevenir la pobreza y la exclusión social.

La literatura científica disponible apunta a que la mejora de las capacidades parentales se relaciona con mejores resultados en el bienestar de los/as niños/as, y que las habilidades parentales pueden ser reforzadas y entrenadas (Comisión Europea, 2011):

La evidencia respecto a la importancia de las habilidades parentales de cara al desarrollo y el bienestar infantil ha atraído el interés de los decisores públicos, de tal forma que los programas orientados a mejorar las capacidades educativas de padres y madres han entrado a formar parte de la agenda de las instituciones en lo que se refiere a la reducción de la pobreza y la exclusión social, y la mejora de los resultados educativos de niños y jóvenes.

\section{Conclusiones: aprendizajes y orientaciones}

El análisis realizado en las páginas precedentes ${ }^{26}$ permite extraer aprendizajes o conclusiones de tres tipos: por un lado, los relativos a los cambios en el contexto socioeconómico que se han producido en los últimos años y que, sin duda, deben tenerse en cuenta a la hora de diseñar las políticas familiares; por otro, los concernientes a la capacidad de protección, especialmente económica, del sistema vasco de apoyo a las familias en relación a los modelos imperantes en Europa; por último, en lo referido a los paradigmas, modelos u orientaciones que se están desarrollando en nuestro entorno -en parte como respuesta a los cambios socioeconómicos señalados- y que podrían, o deberían, ser aplicados en el marco de las políticas familiares en Euskadi.

En relación a la primera de las cuestiones, junto con el descenso de la natalidad y el incremento de la desigualdad, los elementos básicos vienen marcados por el crecimiento de la pobreza entre las familias con hijos/as y por la constatación del creciente peso de la herencia familiar en la igualdad de oportunidades de niños/as y jóvenes. En este artículo se ha intentado argumentar que la herencia social vuelve a ser una cuestión determinante en los procesos de movilidad, debido a que la forma en que las familias invierten en sus hijos/as se caracteriza hoy día por asimetrías sociales cada vez más acusadas. En la sociedad actual las oportunidades siguen estando tan determinadas por la herencia social como en el pasado, de modo que las oportunidades vitales de las personas dependen, fundamentalmente, de la capacidad de sus familias para dotar a aquéllas, durante la infancia, del capital económico, social, cultural, cognitivo y relacional necesario. La creciente importancia de la desigual capacidad de las familias para invertir en el desarrollo de sus hijos/as tiene que ver con los cambios en los modelos productivos de los países occidentales y se relaciona tanto con la desigual transmisión de recursos económicos como, sobre todo, con la desigualdad en la transmisión del capital cultural y humano.

En lo que se refiere, más concretamente, al modelo de prestaciones económicas de apoyo a las familias vigente actualmente en la CAPV -y que, como se ha

${ }^{26}$ Las conclusiones recogidas en este epígrafe hacen referencia tanto al contenido de este artículo como a los datos recogidos en el artículo sobre las políticas familiares en Euskadi publicado en este mismo número de Zerbitzuan. 
dicho, viene determinado tanto por las administraciones autonómica y foral como por la administración estatal, que gestiona y regula las prestaciones de la Seguridad Social-, Euskadi se caracteriza por:

- Un nivel de gasto agregado menor que el que se registra en los demás países de la UE, aun cuando se tenga en cuenta el gasto en educación infantil, que en la CAPV es muy similar a la media de la OCDE. Si bien es cierto que en la CAPV se gasta, en relación al PIB, menos que en otros países de la UE en el conjunto de la protección social, la cuestión verdaderamente relevante estriba en que el gasto social vasco está mucho menos orientado que el de otros países a la infancia y a las familias con hijos/as.

- Se trata, además, de un gasto muy orientado a las desgravaciones fiscales. Este sistema tiene una carencia muy evidente y es que sólo las familias con suficientes ingresos como para poder realizar desgravaciones podrán utilizarlo de forma efectiva, lo que genera un amplio debate sobre si el sistema es suficientemente progresivo y en qué medida podría modificarse para buscar su universalización, como ya se está haciendo en otros países (Ararteko, 2014).

- Si se compara el nivel de protección que los diversos tipos de familias reciben en la CAPV, se observa, por una parte, que las familias con ingresos medios no reciben ningún tipo de ayuda, a diferencia de lo que ocurre en la mayor parte de los países de referencia, que disponen de prestaciones universales de cierta cuantía para las familias con hijos/as. Este nulo nivel de protección se compensa por -o, más bien, se deriva dela menor presión fiscal a la que estas familias están sujetas en relación a las familias de las mismas características de la mayor parte de los países de Europa. Las familias de rentas bajas reciben, por el contrario, un nivel de protección homologable al que reciben las familias del mismo tipo de los países analizados, siempre y cuando accedan a la renta de garantía de ingresos (RGI) y a la prestación complementaria de vivienda (PCV), lo que no siempre ocurre (bien por no cumplir los requisitos, bien por otras causas). Estas familias tampoco reciben prestaciones familiares -a diferencia de lo que ocurre en los demás países de Europa, donde el paquete prestacional al que tienen acceso se compone básicamente de este tipo de ayudas-, y se benefician en menor medida que las familias de rentas medias y altas de las deducciones fiscales por descendientes. Finalmente, las familias sin ingresos reciben mediante la RGI (y siempre que accedan a la PCV) un nivel de protección homologable, o incluso superior, al de otros países de Europa.

Se trata, por tanto, de un modelo atípico en Europa, profundamente selectivo y en cierto modo dual, en el que las familias de rentas medias y altas se benefician de desgravaciones fiscales; $y$ las de rentas bajas o sin ingresos, del sistema de rentas mínimas, abierto a toda la población, pero estrictamente condicionado a la percepción de unos ingresos máximos. Numerosos trabajos han evidenciado, sin embargo, que una de las bases del éxito de los modelos de apoyo a las familias radica en su carácter universal, en la medida en que gozan de mayor apoyo popular, garantizan cuantías más elevadas, están menos expuestos a los recortes y son más fáciles de gestionar. Tal universalidad, en todo caso, no está reñida con un enfoque progresivo, que conceda cuantías más elevadas y apoyos específicos a las familias de menor renta ${ }^{27}$.

Finalmente, en lo que se refiere a las orientaciones que rigen en la actualidad las políticas familiares en Europa, cabe hacer referencia a la adopción del paradigma de la inversión social por parte de las instituciones europeas, lo que sin duda supone una mayor centralidad de las políticas de apoyo a las familias; el énfasis creciente en el desarrollo de servicios destinados a la primera infancia, a partir de la idea de que las desigualdades en el acceso al capital humano se fijan ya en esa etapa; el desarrollo de programas que buscan promover la acumulación de capital desde la infancia como forma de superar la desigual dotación de capital que se produce en la actualidad; la importancia de las herramientas fiscales $y$-dentro de ellas- los créditos fiscales reembolsables como forma de provisión de las prestaciones familiares; $y$, finalmente, el creciente énfasis en los programas de apoyo a la parentalidad.

A partir de estos elementos, cabe plantear algunas orientaciones que podrían servir para reforzar las políticas de apoyo a las familias en Euskadi. Desde ese punto de vista, cabría avanzar en varios niveles:

- Mantener el esfuerzo que en la actualidad se realiza en la CAPV en el ámbito de la atención infantil, reforzando y diversificando los modelos de atención y, fundamentalmente, garantizando su calidad, flexibilidad, cobertura, universalidad y accesibilidad, especialmente de cara a las familias con menos ingresos.

- Seguir avanzando en el desarrollo de programas de parentalidad positiva, tanto a escala autonómica como foral y municipal.

\footnotetext{
${ }_{27}$ "Ante la urgencia de redistribuir mejor, y el hecho de que nadie parece dispuesto a subir los impuestos, quizá sería más apropiado pensar en términos de lo que Theda Skocpol llamaba un 'universalismo focalizado'. Esto consiste en garantizar los servicios básicos a toda la población, y a la vez complementarlos con estrategias específicas para los grupos más vulnerables. En el caso de las guarderías, universalismo es ofrecer educación temprana gratuita a toda la población, focalización es ofrecerla solo a los quintiles más bajos, y universalismo focalizado es ofrecérsela a toda la población, pero complementándola con planes específicos para eliminar barreras de acceso a los niños de los quintiles más bajos (falta de información, por ejemplo) y así garantizar que también se matriculen" (Medina, 2014). El universalismo progresivo, auspiciado también por la Organización Internacional del Trabajo, se define en el ámbito de la salud por la determinación de garantizar que las personas pobres se benefician al menos en igual medida que las más favorecidas en cada una de las fases que llevan a la cobertura universal de un servicio o prestación (Gwatkin y Ergo, 2011).
} 
- Mantener el esfuerzo inversor en el ámbito de la educación y reforzar, muy particularmente, los programas complementarios o compensatorios, orientados al alumnado más desfavorecido, en el marco de una escuela pública inclusiva.

- Desarrollar, inicialmente de forma experimental, sistemas de cuentas de desarrollo individual orientados a la infancia, en la línea del asset based welfare al que se ha hecho referencia.

- Reflexionar sobre los niveles de tributación del patrimonio y, en especial, de las sucesiones y donaciones que, como hemos visto, tienen un efecto relativamente importante en la transmisión de la desigualdad, están sujetas a una tributación muy baja en la CAPV, y podrían ser utilizadas, tal y como se ha propuesto en otros países, para financiar diversas medidas de apoyo a las familias.

- Reflexionar sobre el modelo de protección económica que se ofrece a las familias en Euskadi, considerando de forma integral las diferentes prestaciones y ayudas existentes en la actualidad -desgravaciones fiscales, ingresos mínimos, ayudas familiares de ámbito autonómico y prestaciones familiares de la Seguridad Social-, desde la óptica de la universalidad y la normalización. Esto implica que todas las familias deberían recibir algún tipo de apoyo -aunque no necesariamente del mismo nivel o intensidad-y que el sistema de garantía de ingresos no debería seguir siendo el principal recurso para la protección de las familias de rentas bajas o sin ingresos. En su defecto, cabría pensar en una extensión de las actuales desgravaciones fiscales por descendientes, ampliando su cuantía e introduciendo la figura de los créditos fiscales reembolsables -siguiendo en parte la línea de la reforma fiscal recientemente aprobada por el Gobierno central mediante el recurso al impuesto negativo-, de forma que se redujera, en mayor medida que en la actualidad, la deuda tributaria de las familias de rentas medias y altas, y se generara una prestación periódica neta para las familias de rentas bajas o sin ingresos. Una alternativa a esta opción podría ser la eliminación total de estas y otras deducciones en el
IRPF -así como de una parte de los complementos por hijos/as del sistema RGI-y la financiación mediante la recaudación fiscal adicional obtenida de una prestación autonómica por hijo/a a cargo, de carácter periódico y universal, como ocurre en la mayor parte de los países de nuestro entorno. Esta prestación podría modularse en función de la renta familiar y, en primera instancia al menos, podría orientarse a las familias de dos o más hijos/as, como ocurre en Francia. Se trataría, en este sentido, de seguir la trayectoria universalista, frente a la fiscal, que defienden Ferrarini, Nelson y Höög (2012), habida cuenta del menor nivel de protección que ofrecen los sistemas basados en las herramientas fiscales ${ }^{28}$.

- A más largo plazo, en cualquier caso, resulta imprescindible una reorientación más profunda del modelo de protección social de la CAPV que tenga en cuenta, fundamentalmente, la necesidad de invertir en la infancia y de tomar medidas que reduzcan el peso de la herencia social y garanticen la igualdad de oportunidades. Ello exige invertir de forma eficiente en servicios educativos, de cuidado infantil y de apoyo parental, y reorientar completamente el actual modelo de prestaciones económicas, de forma que priorice, en la línea del paradigma de la inversión social, la protección de las familias con hijos/as y las personas jóvenes.

- Podría ser interesante en este sentido seguir el modelo británico, que ha creado una Comisión sobre Pobreza Infantil y Movilidad Social, de carácter independiente, que evalúa los avances realizados por la administración británica en esta materia.

- En cualquier caso, debe tenerse en cuenta que en el Estado español, como en muchos de los países de Europa, las prestaciones familiares -incluyendo las relacionadas con los permisos de paternidad y maternidad-y buena parte de las prestaciones de protección social son gestionadas por la Seguridad Social, respecto a la cual las instituciones vascas carecen de competencias. 


\section{Bibliografía referenciada}

ADEMA, W. (2012): "Setting the scene: The mix of family policy objectives and packages across the OECD", Children and Youth Services Review, vol. 34, n- 3, págs. 487-498.

ARARTEKO (2014): Políticas de apoyo a las familias en Euskadi. Análisis y propuestas / Familiei laguntzeko politikak Euskadin: azterketa eta proposamenak, Vitoria-Gasteiz, Ararteko.

BLANDEN, J.; GREGG, P.; y MACMILLAN, L. (2013): Intergenerational Persistence in Income and Social Class: The Impact of Within-group Inequality, serie CEP Discussion Paper, no 1.242, Londres, Centre for Economic Performance.

COMISIÓN EUROPEA (2014): Comprender las políticas de la Unión Europea: empleo, asuntos sociales e inclusión, Luxemburgo, Oficina de Publicaciones de la Unión Europea [<http:// europa.eu/pol/pdf/flipbook/es/employment_ es.pdf〉].

COMITÉ TÉCNICO DE LA FUNDACIÓN FOESSA (2014): "La fractura social se ensancha. Avance de resultados de la Encuesta sobre Integración y Necesidades Sociales, 2013", en COMITÉ TÉCNICO DE LA FUNDACIÓN FOESSA, Precariedad y cohesión social, serie Análisis y Perspectivas, Madrid, Fundación Foessa.

CORAK, M. (2013): Income Inequality, Equality of Opportunity, and Intergenerational Mobility, serie IZA Discussion Paper, nํㅜ.520, Bonn, IZAForschungsinstitut zur Zukunft der Arbeit.

DALY, M. (ed.) (2012): La parentalidad en la Europa contemporánea: un enfoque positivo, serie Informes, Estudios e Investigación, Madrid, Ministerio de Sanidad, Servicios Sociales e Igualdad.
DEPARTAMENTO DE EMPLEO Y ASUNTOS SOCIALES (2012): Encuesta de Pobreza y Desigualdades Sociales 2012. Principales resultados, Vitoria-Gasteiz, Eusko Jaurlaritza-Gobierno Vasco.

ESPING-ANDERSEN, G. (2005): "Social inheritance and equal opportunity policies", en DELORENZI, S. et al. (eds.), Maintaining Momentum. Promoting Social Mobility and Life Chances from Early Years to Adulthood, Londres, Institute for Public Policy Research, págs. 14-30.

- (2002): Why We Need a New Welfare State, Nueva York, Oxford University Press.

ESPING-ANDERSEN, G.; y PALIER, B. (2010): Los tres grandes retos del Estado del bienestar, Barcelona, Ariel.

ESPING-ANDERSEN, G. et al. (2013): El déficit de natalidad en Europa. La singularidad del caso español, serie Colección Estudios Sociales, nํ36, Barcelona, Obra Social La Caixa.

ESPING-ANDERSEN, G. et al. (2012): “Child care and school performance in Denmark and the United States", Children and Youth Services Review, vol. 34, nํㅡ 3, págs. 576-589.

EUROSTAT: European Union Statistics on Income and Living Conditions (EU-SILC), Bruselas, Eurostat [<http://epp.eurostat.ec.europa.eu/portal/ page/portal/microdata/eu_silc>].

-: Demographic balance and crude rates, Bruselas, Eurostat [rhttp://appsso.eurostat.ec.europa.eu/nui/ show.do?dataset $=$ demo_gind\&lang=en〉].

FERNÁNDEZ-ALBERTOS, J. (2014): “Nuestra desigualdad”, El Diario.es, 1-7-2014 [<http://www.eldiario.es/ piedrasdepapel/desigualdad_6_276882310. html>].

FERRARINI, T.; NELSON, K.; y HÖÖG, H. (2012): “From universalism to selectivity: Old wine in new 
bottles for child benefits in Europe and other countries", en MARX, I.; y NELSON, K. (eds.), Minimum Income Protection in Flux, serie Reconciling Work and Welfare in Europe, Nueva York, Palgrave MacMillan, págs. 137-160.

FIELD, F. (2010): The Foundation Years: Preventing Poor Children Becoming Poor Adults. The Report of the Independent Review on Poverty and Life Chances, Londres, Cabinet Office.

FRANCISCO DE, A.; y RAVENTÓS, D. (2003): “¿Por qué Rawls interesa a la izquierda?", Viento Sur, no 67.

GARGARELLA, R. (2012) “Democracia de propietarios”, en GARGARELLA, R. (coord.), Seminario de Teoría Constitucional y Filosofía Política: una mirada igualitaria sobre el constitucionalismo [khttp://seminariogargarella.blogspot.com. es/2012/06/democracia-de-propietarios. html $)$.

GOLDSTEIN, J. R. et al. (2013): "Fertility reactions to the 'Great Recession' in Europe: Recent evidence from order-specific data", Demographic Research, vol. 29, nํㅜ 4, págs. 85-104.

GWATKIN, D. R.; y ERGO, A. (2011): "Universal health coverage: Friend or foe of health equity?", The Lancet, vol. 377, no 9.784, págs. 2.1602.161 [rhttp://dx.doi.org/10.1016/So1406736(10)62058-2>].

HECKMAN, J. et al. (2006): "The dollars and cents of investing early: Cost-benefit analysis in early care and education", Zero to Three, $\mathrm{n}$ - julio, págs. 10-17.

HERMIDA, P.; y NOGUERA, J. A. (2013): “Integración de impuestos y prestaciones: una vía innovadora para la reforma de la protección social", Documentación Social, nํ169, págs. 105-125.

INDEPENDENT COMMISSION ON SOCIAL MOBILITY (2009): Report from the Independent Commission on Social Mobility, Londres, Social Mobility and Child Poverty Commission.

INE (2014): Encuesta de Condiciones de Vida. Base 2013, Madrid, Instituto Nacional de Estadística [<http://www.ine.es/jaxi/ menu.do?type $=$ pcaxis \& path $=/$ t $25 /$ p453\&file=inebase $>$ ].

-: Indicadores demográficos básicos, Madrid, Instituto Nacional de Estadística [<http://www.ine.es/ jaxi $/$ menu.do?type $=$ pcaxis $\&$ path $=\% 2 \mathrm{Ft} 20 \% 2 \mathrm{Fp}$ 318\&file $=$ inebase $\& L=0\rangle]$.

MARTÍNEZ CELORRIO, X.; y MARÍN SALDO, A. (2013): Crisi, desigualtats i benestar vulnerable. Anàlisi longitudinal del PaD (2003-2009), serie Informes Breus, $n \div$ 1, Barcelona, Fundació Jaume Bofill.

- (2012): "Educación y movilidad social en España”, en MARTÍN PATINO, J. M. et al. (dirs.), Informe España 2012: una interpretación de su realidad social, serie Informes, nำ19, Madrid, Fundación Encuentro.

MORGAN, K. J. (2012): Promoting social investment through work family policies: Which nations do it and why?", en MOREL, N.; PALIER, B.; y PALME, J. (eds.), Towards a Social Investment Welfare State? Ideas, Policies and Challenges, Bristol, Policy Press, págs. 153-179.
MOREL, N.; PALIER, B.; y PALME, J. (eds.) (2012): Towards a Social Investment Welfare State? Ideas, Policies and Challenges, Bristol, Policy Press.

OCDE (2010): Economic Policy Reforms 2010: Going for Growth. Structural Policy Indicators, Priorities and Analysis, París, OECD Publishing.

- (2009): Doing Better for Children, París, Organización para la Cooperación y el Desarrollo Económicos.

O’NEILL, M.; y WILLIAMSON, T. (2014): Property-owning Democracy: Rawls and Beyond, Londres, WileyBlackwell.

PEUGNY, C. (2013): Le destin au berceau. Inégalités et reproduction sociale, serie La République des Idées, París, Éditions du Seuil, La République des Idées.

PIKETTY, T. (2008): L'économie des inégalités, París, Éditions La Découverte.

PIKETTY, T.; y ZUCMAN, G. (2014): Wealth and Inheritance in the Long Run, Londres, London School of Economics.

PRABHAKAR, R.; ROWLINSON, K.; y WHITE, S. (2008): How to Defend Inheritance Tax, serie Fabian Ideas, $\mathrm{n}$ 623, Londres, Fabian Society.

QUERALT, J. (2012): “Dos versiones de la democracia de propietarios rawlsiana", Revista Argentina de Teoría Jurídica, vol. 13, págs. 1-24.

SARASA, S. (2008): "Perdedores en tiempos de bonanza", en RENES, V. (coord.), VI Informe sobre Exclusión y Desarrollo Social en España 2008, Madrid, Fundación Foessa, págs. 263-277.

SIIS CENTRO DE DOCUMENTACIÓN Y ESTUDIOS (2013): Fiscalidad, activación y apoyo a las familias: el papel de las deducciones reembolsables. Panorama internacional, Donostia-San Sebastián, Diputación Foral de Gipuzkoa [shttp://www.siis.net/documentos/informes/ Fiscalidad.pdf $\rangle]$.

- (2012a): Políticas de apoyo a las familias en la Unión Europea y en la CAPV, Vitoria-Gasteiz, Ikuspegi@k. Observatorios de Asuntos Sociales.

- (2012b): Activación y derecho a la inclusión en el marco de las políticas de empleo y de garantía de ingresos en la CAPV / Aktibazioa eta gizarteratzako eskubidea, EAEko enpleguko eta diru-sarrerak bermatzeko politiken esparruan, Vitoria-Gasteiz, Eusko Jaurlaritza-Gobierno Vasco.

USSHER, K. (2012): "Taking the long view on welfare policy", en DENHAM, J. (ed.), The Shape of Things to Come, Londres, Fabian Society, págs. 55-63.

WALDFOGEL, J. (2005): "Social mobility, life chances and the early years", en DELORENZI, S. et al. (eds.), Maintaining Momentum. Promoting Social Mobility and Life Chances from Early Years to Adulthood, Londres, Institute for Public Policy Research, págs. 31-55.

ZALAKAIN, J. (2013): "Tendencias y prácticas innovadoras en inclusión social. Perspectiva internacional", Lan Harremanak, vol. 29, nํII, págs. 175-216. 
